TI 2017-028/VIII

Tinbergen Institute Discussion Paper
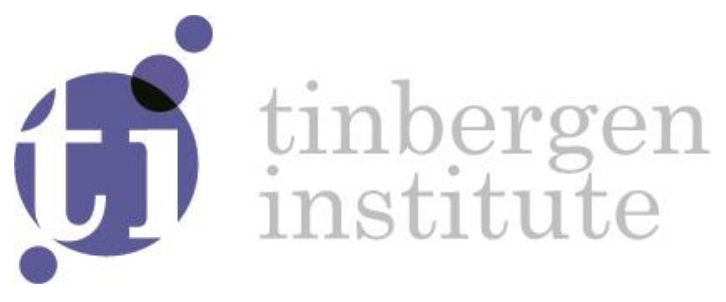

\title{
Measuring diverging house prices
}

\section{Revision: April 16, 2018}

\author{
Jan Rouwendal ${ }^{1}$ \\ Mark van Duijn ${ }^{2}$
}

${ }^{1}$ Department of Spatial Economics, VU University; Tinbergen Institute

${ }^{2}$ Department of Economic Geography, University of Groningen 
Tinbergen Institute is the graduate school and research institute in economics of Erasmus University Rotterdam, the University of Amsterdam and VU University Amsterdam.

Contact: discussionpapers@tinbergen.nl

More TI discussion papers can be downloaded at http://www.tinbergen.nl

Tinbergen Institute has two locations:

Tinbergen Institute Amsterdam

Gustav Mahlerplein 117

1082 MS Amsterdam

The Netherlands

Tel.: +31(0)205984580

Tinbergen Institute Rotterdam

Burg. Oudlaan 50

3062 PA Rotterdam

The Netherlands

Tel.: +31(0)10408 8900 


\title{
Measuring diverging house prices
}

\author{
Jan Rouwendal ${ }^{1,2}$ and Mark van Duijn ${ }^{3}$ \\ ${ }^{1}$ Department of Spatial Economics, VU University, De Boelelaan 1105, 1081 HV Amsterdam. \\ 2 Tinbergen Institute, Gustav Mahlerplein 117, 1082 MS Amsterdam. \\ ${ }^{3}$ Department of Economic Geography, University of Groningen, Landleven 1, 9747 AD Groningen.
}

This version: April 16, 2018

\begin{abstract}
Real estate price indexes summarize the evolution of all property prices in a single number, while actual price movements often differ among market segments. We develop a methodology for measuring prices as a flexible function of a one-dimensional quality measure - housing services for residential real estate - and apply it to test for the common assumption of identical price movements in all parts of the market. Our approach is based on a generalization of the familiar (constant unit price) Muth model to a situation of in which the unit price of housing services may depend on the quality level. We apply the method to a rich set of transaction data referring to Amsterdam in the period 1985-2013. We estimate an indicator of housing services based only on the ranking of house prices in postcode areas during periods of three months and compare the results to conventional hedonic price equations that embody the assumption of a unit price for housing services that does not depend on quality. We develop a test for a constant price per unit of housing services and reject it on the basis of price differences occurring over time as well as over space.
\end{abstract}

Keywords: housing price, housing quality, Muth model, affordability

JEL Classification Codes: R31, R21, D40 



\section{Introduction}

The amount of real estate in any advanced economy is enormous and adequate measurement of its value is of considerable importance. For instance, the determination of the property tax and the possibility to get a mortgage loan of a given size depend on the value of a building. There exists abundant evidence that prices of different types of housing evolve differently over time (see, for instance, Guerrieri et al. (2013) for US MSA's, Landvoigt et al. (2012) for San Diego, Liu et al. (2014) for Phoenix $)^{1}$ and similar things happens probably in other real estate markets. This evidence contrasts with the existing practice to describe the evolution of house prices - for the complete quality range - in large areas by a single number for each period (for instance, the S\&P/Case-Shiller house price index). ${ }^{2}$ Summarizing the change of prices in the whole housing stock by a single number implies the risk of drawing wrong inferences with respect to, for instance, the affordability of housing for low income groups which typically can buy only in the lower quality segments where price developments may differ from the average.

The practice of using a single number to analyze house price evolution is explained, at least in part, by the fact that there is no widely accepted methodology for describing the evolution of the prices of houses of different qualities. The Case-Shiller index compares prices of the same houses sold repeatedly at different points in time and thus controls implicitly for all quality aspects that do not change over time without their measurement. However, if quality is not measured, quality-dependent differences in price development cannot be observed. A conventional hedonic price index, on the other hand, measures quality on the basis of housing

\footnotetext{
${ }^{1}$ See, for instance, http://www.ft.com/cms/s/0/a8d4cae2-afdd-11e1-a025-00144feabdc0.html for London and http://www.huffingtonpost.ca/2013/01/04/house-prices-sales-toronto n 2410200 .html for Toronto.

${ }^{2}$ Liu et al. (2014) discuss the potentially misleading effect of this practice.
} 
characteristics, but deals with differences in house prices over time or space as if they are identical for all houses. ${ }^{3}$

Observations of diverging house prices are often based on classifications of houses in broad price classes. Houses with prices that pass the border between these classes over time then cause complications. Moreover, it can be argued that the observations are affected by differences in the composition of subsets of sold houses over time. For instance, within the class of luxury houses very expensive houses may be sold more frequently during boom periods. McMillen (2008) investigated this issue for the Chicago metropolitan area and concluded that changes in the types of houses sold and their location are unable to fully explain the higher appreciation rates for high-priced homes, but different conclusions may hold for other places and times.

Quantile regression, see e.g. Zietz et al. (2008), offers the possibility to investigate differences in the changes of house prices across the distribution of transaction prices. Unconditional quantile analysis could be used to consider the evolution of the price at any quantile of the price distribution. However, there is no reason to expect that the quality level corresponding to a particular quantile is constant over time. Conditioning on housing characteristics implies imposing proportional price changes on houses that differ in quality for each quantile. Alternatively, one can estimate models for the probability that houses in certain classes defined by characteristics command a price exceeding a particular quantile of the price distribution in each year, but such information is less easy to interpret than a price index that is conditioned on a particular quality level as results from the approach of the present paper.

We propose a methodology for measuring (potentially) diverging house prices that is based on the concept of housing services introduced by Muth (1960). Housing services are an

\footnotetext{
${ }^{3}$ Quality dependent differences in house prices could in principle be dealt with through interactions between housing attributes and time or space, but such specifications are seldom, if ever, used.
} 
indicator of the quality of a house: the higher the number of housing services a house offers, the higher is its quality. Housing services can be interpreted as the quantity dimension of housing consumption and their introduction made the conventional tools of microeconomic analysis applicable to the housing market. Muth (1960) proposed to interpret the enormous heterogeneity of housing as a manifestation of a simple underlying structure: each house offers to its occupant a quantity of a completely homogeneous commodity, called housing services, which is available at a given unit price. Differences in housing quality were thus interpreted as differences in the quantity of housing services. ${ }^{4}$ Rents are the product of a constant price per unit of housing services and the number of units consumed. Similarly, house prices are the discounted values of the flow of future housing services to be expected from a house.

Muth's approach has been very fruitful and is standard in economic analysis of housing markets (see, for instance, the reviews of Arnott, 1987, for theory and Olsen, 1987, for empirics and Epple et al., 2015, for a recent study). Perhaps the best known application is in the 'AlonsoMuth-Mills' model that is the workhorse of urban economics. In that model the price of housing services depends on the location relative to the central business district. In practice there are many other potential reasons (for instance, local public goods) why house prices differ over neighborhoods and a common approach to deal with this is the use of area fixed effects.

The concept of housing services can be derived from a basic model in which consumers derive utility from housing characteristics and other goods if preferences are separable in housing characteristics, ${ }^{5}$ see Rouwendal (1998). Under this assumption, house prices are a function of the

\footnotetext{
${ }^{4}$ In what follows we will use housing quality and the quantity of housing services as synonyms.

${ }^{5}$ That is, if preference refer to housing characteristics $x$ and other consumption goods $c$ it is required that the utility function $u(x, c)$ can be written as $u(x, c)=U(h(x), c)$ where $h(x)$ is a subutility function for housing characteristics. The value of $h$ can be interpreted as the quatity of housing services, which is an aggregate of the housing characteristics.
} 
amount of housing services it provides, but the linearity of this function is not implied. The model suggested by this approach is therefore the one used here.

A constant unit price for housing requires that the price ratio of houses that differ in quality must be constant over time, which excludes diverging or converging house prices for different segments of the market. Such a constant price per unit will only occur in a market where arbitrary packages of housing services can be constructed and changed at will. Indeed, the conventional approach is to regard the housing stock as a number of units of housing services that can be distributed arbitrarily over the households participating in a market, or to assume that additional housing services can be produced without delay at a given price per unit and that they can also be disposed of without cost.

In reality it is not so easy to unbundle and re-bundle existing packages of housing services. A more realistic approach would be to take the number of houses of a given quality as given (at least in the short run) and allow for differences in the unit price across the quality levels. That is the approach we propose in this paper. We thus keep Muth's assumption that housing quality can be described by a one-dimensional indicator referred to as housing services, but we allow the price of housing to be a general - nonlinear - increasing function of the units of housing services. Just like the unit price can change over time in the standard approach, this increasing function can also differ between geographical markets and over time on a given market.

We develop a methodology that makes this idea operational. The basic observation is that, in our generalized Muth model without constant unit prices, sales prices reflect the ranking of houses on the basis of quality. That is, in a given - temporary or geographical - market houses of higher quality sell for higher prices, implying that the price ranking reveals the quality ranking. A given difference in quality may correspond to price differences that vary over periods and geographical markets. To allow for such differences, we develop a procedure to estimate the units 
of housing services produced by any house using only information about the quality ranking of houses sold in small spatial areas within a period of one quarter. With this estimate of the number of housing services in hand, we can subsequently estimate the function that describes the relationship between housing services and house prices on a given market by flexible parametric or non-parametric techniques.

We then develop a method for testing the unit price hypothesis. There are two aspects we consider. The first is that if the unit price is independent of quality, the prices of houses of all quality levels evolve parallel to each other in time. We test this property by focusing on the difference between the log prices of houses of various quality levels in different years. Then we extend the analysis by allowing area specific effects. This introduces the second aspect: the areaspecific effects should be identical at all quality levels. We also test this property. We find that both over time and across space the unit price hypothesis is rejected by the data.

The paper is organized as follows. The next section introduces the model and the estimation strategy. Section 3 discusses the data. Section 4 reports estimation results for the Amsterdam housing market in the period 1990-2011. In sections 5 and 6 we develop our test for the constant unit price and report the results. Section 7 summarizes and concludes.

\section{Housing services with flexible unit prices}

\subsection{The standard approach and the loglinear hedonic price function}

The standard approach to housing demand in economics, introduced originally by Muth (1960), interprets the rent or price of a house as the product of a unit price and a quantity of an imaginary commodity called housing services. Formally, this can be expressed as:

$P=\Pi H$ 
where $\Pi$ denotes the unit price of housing services and $H$ the quantity of housing services. On a given market at a given time, differences in house prices only reflect differences in housing quality, or in the quantity of housing services provided by a house. Ranking the houses in the market on the basis of their price is equivalent to ranking them on the basis of their quality. The constant unit price implies that the size of the price difference between two houses is proportional to the difference in quality. More specifically, the quality ratio of any pair of houses is exactly reflected in their price ratio. It is this property of Muth's concept that imposes that the prices of all kinds of houses move in proportion to each other. ${ }^{6}$

Although housing services is an imaginary commodity, the concept is clearly intended to reflect housing quality and it is therefore natural to link it to housing characteristics. Doing so, we assume:

$H=H(x, \xi)$

where $x$, a $K$-dimensional vector, and $\xi$, a scalar, represent observed and unobserved housing attributes, respectively. ${ }^{7}$ We assume a log-linear specification of the function $H($.$) :$

$\ln H=\sum_{k} \beta_{k} X_{k}+\xi$

In combination with (1), this gives the familiar log-linear hedonic price function:

$\ln P=\ln \Pi+\sum_{k} \beta_{k} X_{k}+\xi$

If the function is estimated for different markets, $m$, or for the same market over different periods, $t$, the unit price $\Pi$ is allowed to differ and the different values, say $\Pi_{m t}$, then reflect the price of a house with any given set of characteristics $\{X, \xi\}$ in different circumstances. One can choose an arbitrary set of characteristics as a reference and interpret the price of the corresponding house as the unit price for housing services. It is thus clear that, in this approach, the prices of all houses

\footnotetext{
${ }^{6}$ See Rouwendal (1998) for a demand model that leads to this specification.

${ }^{7}$ The $X$ 's may include transformations and cross products of the basic housing characteristics.
} 
move in proportion to each other, which is consistent with Muth's interpretation of the housing market as referring - behind a veil of apparent heterogeneity - to a standard homogeneous commodity, housing services, that is available in continuous quantities at a constant price per unit.

\subsection{Generalization to flexible unit prices}

The generalization we propose in this paper drops the assumption of a fixed price per unit, but keeps the concept of housing services. That is, instead of (1) we assume:

$P=F(H)$

where $F($.$) is an unspecified increasing function, and H$ is specified in (2). Assuming differentiability, the marginal price of a unit of housing services is $\partial F / \partial H$ and it is constant only in the special case of a linear function of $F(H){ }^{8}$ Apart from the requirement that it should be positive, we do not impose any restriction on the marginal price $\partial F / \partial H$ and the function $F$ may therefore be partly or completely convex as well as concave. (5) can be interpreted as a hedonic price function in which house prices are related to housing characteristics via the single index $H$. Note, however, that (5) is a significant generalization of (1).

We maintain the assumption that housing services are a log-linear function of the housing characteristics. Substitution of (3) into (5) then shows the single-index model explicitly: ${ }^{9}$

$P=F\left(\sum_{k} \beta_{k} X_{k}+\xi\right)$

This is the specification that we will take to the data.

The estimation of single index models has been considered by, among others, Ichimura (1993), Klein and Spady (1993), and Horowitz and Härdle (1996). This literature considers

\footnotetext{
${ }^{8}$ Muth's approach does not only assume linearity but proportionality, i.e. a zero intercept of the linear function.

${ }^{9}$ The logarithmic transformation can be absorbed in the function $F$.
} 
estimation of the vector of coefficients $\beta$ for the case in which $\xi=0$, while adding an error term to the function $F .{ }^{10}$ Unobserved quality characteristics are thus absent in the single index. The neglect of unobserved quality aspects makes this approach less suitable for the problem we consider here.

The presence of unobserved (by the researcher) quality aspects in housing is a priori highly probable and potentially important. Before buying a house households typically inspect it physically and very often one's impression and valuation of the house depend substantially on the outcome. This suggests strongly that even extensive information about the house and the neighbourhood in which it is located are an imperfect substitute for observing and experiencing the house oneself because some relevant aspects cannot be communicated otherwise in an appropriate way. These omitted variable concerns have always been present in the hedonic price literature and they are often difficult to overcome. We are therefore unwilling to assume that there is no unobserved heterogeneity.

To find an alternative that does account for unobserved heterogeneity, we suggest an approach that exploits the ranking of houses based on the transaction price and the number of housing services. The fact that $F($.$) is increasing implies that the ranking of houses on the basis$ of their prices coincides with the ranking on the basis of the housing services. That is, for any pair of houses $(i, j)$ observed in a given market in the same period and using a suffix to indicate the houses to which the characteristics refer, we must have:

$P_{i}>P_{j}\left(\Leftrightarrow H_{i}>H_{j}\right) \Leftrightarrow \sum_{k} \beta_{k} X_{i k}+\xi_{i}>\sum_{k} \beta_{k} X_{j k}+\xi_{j}$

This set of inequalities summarizes the information the data provide about the quality of houses in a sample referring to a given market in a given period. It tells us that prices indicate a ranking

\footnotetext{
${ }^{10}$ That is, this literature considers estimation of an equation $P=F\left(\sum_{k} \beta_{k} X_{k}\right)+\varepsilon$, with $\varepsilon$ an error term.
} 
of the houses on the basis of quality. This ranking does not depend on the curvature of the function $F$, only on the fact that this function is increasing.

The inequality on the right-hand side of (7) reveals less information than is used in the standard Muth model. Although we have already assumed a specific functional form (a linear specification), not all its coefficients are identified. Adding a constant on both sides or multiplication of both sides by the same constant leaves the inequality unchanged. Without loss of generality, we may therefore set the value of the intercept at 0 and set the value of one other coefficient - which we take to be the one referring to the characteristic listed first, $\beta_{1}-$ equal to $1^{11}$

This normalization is still insufficient to allow us to determine the values of the coefficients $\beta_{k}$. For instance, it is easy to satisfy the inequalities (7) for arbitrary values of the $\beta_{k} \mathrm{~s}$ by choosing appropriate values of the $\xi_{j}$ s. We must therefore impose more structure on the problem. One possibility is to minimize the sum of the squared $\xi_{j}$ s subject to the constraints (7). In Appendix A we show that this 'least squares' approach leads to a quadratic mathematical program that is, unfortunately, not easy to solve for large numbers of observations.

An alternative approach is to make assumptions about the distribution of the $\xi_{j} \mathrm{~s}$. For instance, one may suppose that unobserved housing characteristics can be considered as independent random draws from a given probability distribution that is known up to the values of one or more parameters. Then every $\xi_{j}$ is a random draw from some distribution $G(\xi)$. This assumption allows us to write down expressions for the probability that the system of inequalities (7) is valid and use maximum likelihood estimation. A particularly convenient choice is the

\footnotetext{
${ }^{11}$ The literature on single index models referred to earlier uses a similar normalization.
} 
Extreme Value type I distribution $G(\xi)=e^{-e^{-\xi / \sigma}}$ where $\sigma$ indicates the variance of $\xi .{ }^{12}$ It allows us to apply the results of Beggs, Cardell and Hausman (1981) on the full ranking of a set of choice alternatives. These authors show that if one ranks $I$ objects based on indicators $H_{i}=$ $\sum_{k} \beta_{k} X_{i k}+\xi_{i}, i=1 \ldots I$ with the $\xi_{i}$ 's as just discussed and one lists the objects on the basis of their rank (i.e. the one with the highest $H_{i}$ has $i=1$, etc.), the likelihood $L$ of the observed ranking of the objects is:

$L=\frac{e^{\sum_{k} \gamma_{k} X_{1 k}}}{\sum_{i \geq 1} e^{\sum_{k} \gamma_{k} X_{i k}}} \frac{e^{\sum_{k} \gamma_{k} X_{2 k}}}{\sum_{i \geq 2} e^{\sum_{k} \gamma_{k} X_{i k}}} \frac{e^{\sum_{k} \gamma_{k} X_{3 k}}}{\sum_{i \geq 3} e^{\sum_{k} \gamma_{k} X_{3 k}}} \cdots \frac{e^{\sum_{k} \gamma_{k} X_{(I-1) k}}}{e^{\sum_{k} \gamma_{k} X_{(I-1) k}}+e^{\sum_{k} \gamma_{k} X_{I k}}}$,

In this equation $\gamma_{1}=\frac{1}{\sigma}$, because of the normalization $\beta_{1}=1$ and $\gamma_{k}=\frac{\beta_{k}}{\sigma}, k=2 \ldots K$. The righthand side of (8) is a product of logit choice probabilities. The first of these gives the logit probability that alternative 1 is ranked higher than $2,3, \ldots I$, the second the probability that alternative 2 is ranked higher than $3,4, \ldots I$, et cetera. Maximizing this likelihood with respect to the coefficients $\gamma_{k}$ gives us estimates for these parameters, and hence of $\beta_{k}, k=2 \ldots K$ and $\sigma$.

In the empirical work below we apply this methodology to the price ranking of houses sold in a given market, defined as a postcode area in one quarter. Details are provided below. We also use a generalization of the model that allows the spread of the unobserved quality $\sigma$ to differ over postcode areas.

If we have estimates of the number of housing services 'produced' by a house, we can estimate the price function $F$. The proper argument of this function is $H=\sum_{k=1}^{K} \beta_{k} X_{k}+\xi$. However, we can only estimate the housing services of any house $i$ in the sample as $\widehat{H}_{i}=X_{i 1}+$ $\sum_{k}\left(\hat{\gamma}_{k} / \hat{\gamma}_{1}\right) X_{i k}$ since we do not observe the realization of the last term, $\xi$. The price function is in general nonlinear, so mean regression of the transaction prices $P_{i}$ on $\widehat{H}_{i}$ does not make sense.

\footnotetext{
${ }^{12}$ This distribution does not have mean 0 , but since we are only interested in the implied ranking, this is immaterial.
} 
However, median regression will uncover the relationship between housing services and house prices. We thus apply this tool in the empirical investigations that are reported below.

We will estimate $F($.$) in (5) by postulating that P_{i}$ is either a flexible parametric function (e.g. a polynomial) or a non-parametric (e.g. local polynomial) function of $\widehat{H}_{i}$, using median regression. The results allow us to trace the evolution of house prices of any given level of quality over time. Alternatively, we can do such an analysis for observations referring to a set of geographical markets in a given time interval and compare the prices of houses of a given quality level at different locations.

It is useful to compare the approach just outlined with conventional OLS or median regression. Then one would typically estimate an equation like:

$\ln P=\beta_{0}^{m}+\sum_{k=1}^{K} \beta_{k} X_{k}+\xi, m=1 \ldots M$

One market - say the first one - serves as the reference and the price index $P I_{m}$ for other markets would then be determined as $P I_{m}=\exp \left(\beta_{0}^{m}-\beta_{0}^{1}\right)$. If one compares any pair of houses with a given set of characteristics in market $m$ and the reference, the price ratio will always be the same. ${ }^{13}$ This contrasts sharply with the approach outlined above in which house prices are a market-specific increasing function of quality, that is: $P=F_{m}\left(\sum_{k} \beta_{k} X_{k}+\xi\right)$, compare (5) above, while the coefficients $\beta_{k}$ are identical for all markets.

\section{Data}

We use transaction data for the municipality of Amsterdam in the period January 1985 - June 2013. This dataset consists of all housing transactions realized by members of the Dutch

\footnotetext{
${ }^{13}$ The reasoning is (of course) similar when the same market is observed in different periods.
} 
association of real estate agents (NVM). NVM brokers are on average involved in $70 \%$ of the transactions in the Netherlands.

Amsterdam is the largest city of the Netherlands. The canal belt that dates back to the 17 th century and surrounds most of the medieval inner city is world-famous. The city has grown further since the 19th century and there is a lot of heterogeneity in the neighborhoods of the municipality. To take this into account, we concentrate on variation within 4 position postcode areas. Figure 1 presents a map of these areas in the municipality of Amsterdam and parts of the surrounding municipalities. ${ }^{14} \mathrm{~A}$ few of these postcodes (e.g. 1027) are largely agricultural, some others (e.g. 1041) are predominantly industrial, but in the large majority of them most of the land

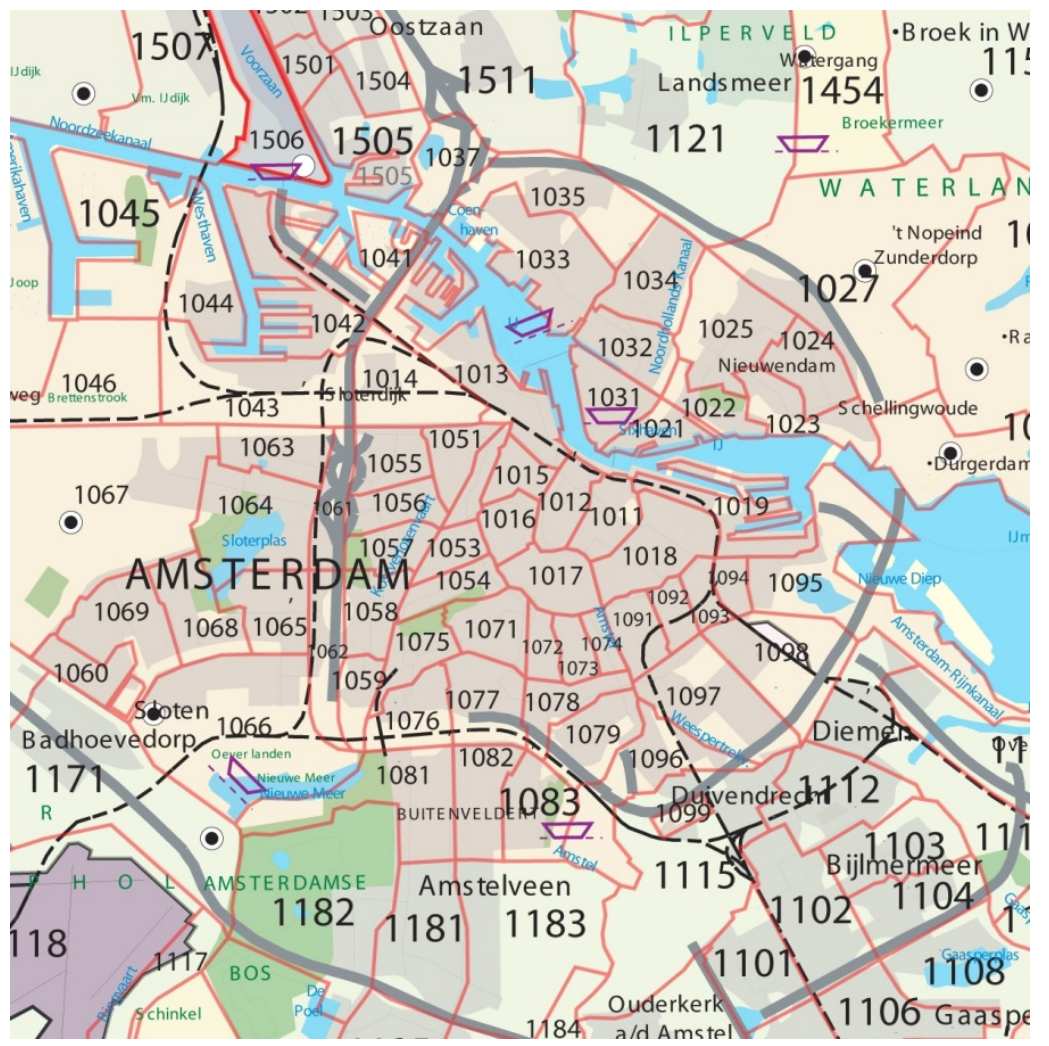

\section{Figure 1 Postcode areas in Amsterdam}

\footnotetext{
${ }^{14}$ The ancient inner city dating back to the Middle Ages has postcode 1012, and most of the canal belt is included in the areas 1016 and 1017. Surrounding the 17th century city is another belt, of 19th century neighbourhoods. Some of them are quite popular, for instance the postcode area 1071 which is close to the Rijksmuseum, the Concert Hall and the Vondel park. Even further from the city centre are the 20th century neighbourhoods like the Bijlmer (post code area 1101 and higher).
} 


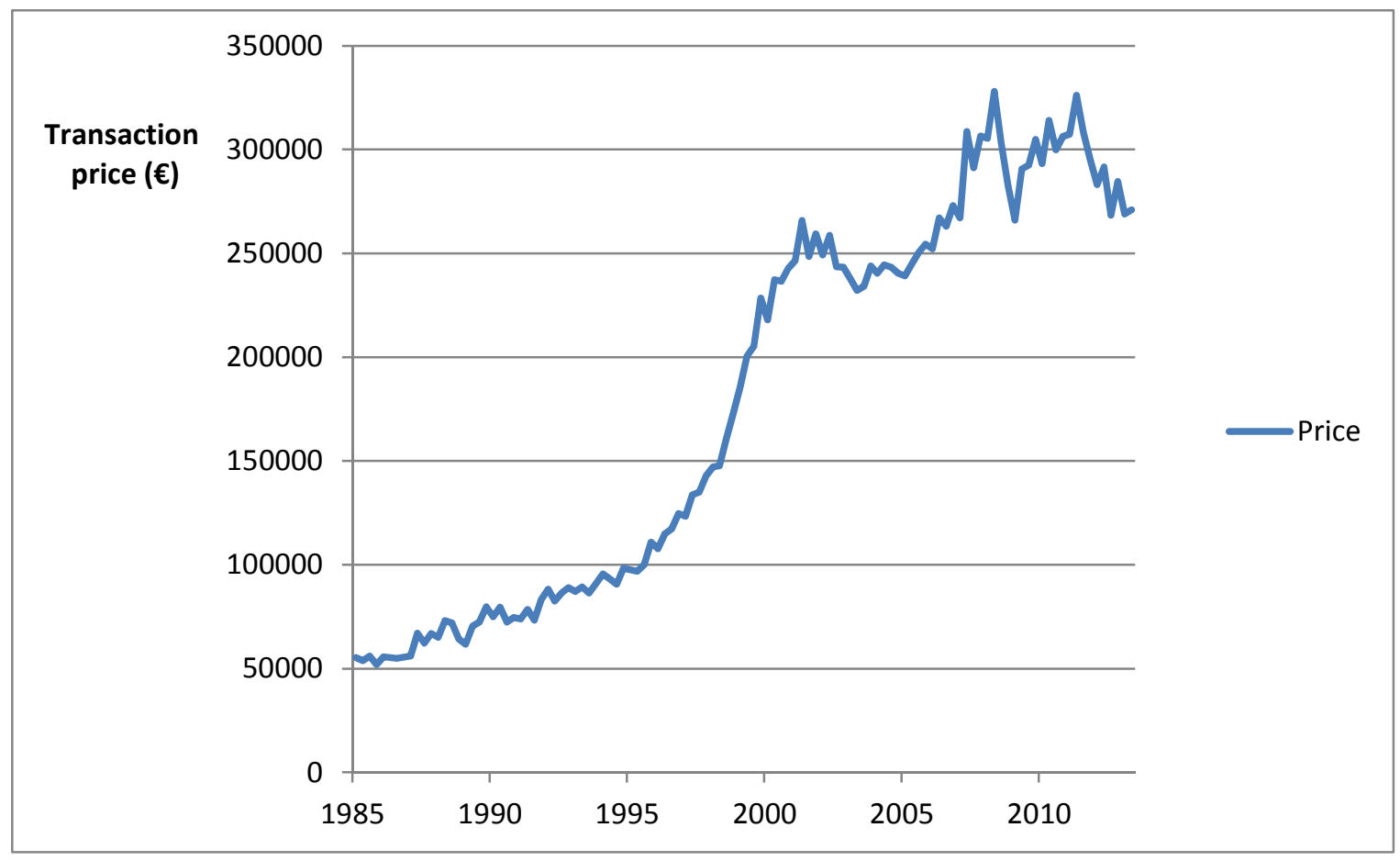

Figure 2 Average transaction piece per quarter January 1985 - June 2013

is in residential use. The average number of persons per postcode area is 4,000, which suggests that the total number of properties is between 1,500 and 2,000. The share of owner-occupied housing in Amsterdam as a whole was between $20 \%$ and $30 \%$ in the period considered, and shows considerable local variation.

Our observations refer to the period January 1985 - June 2013. In the 1980s the Dutch housing market was recovering from a substantial bust that started around 1980 when monetary authorities restricted money supply and real interest rates increased considerably. During the 1990s a new boom period set on, that lasted until 2007. After the onset of the crisis in 2007, transaction prices dropped sharply in 2008, then recovered, but started falling again by the end of 2011.

An interesting aspect of Figure 2 is that it suggests that within years there can be non-negligible changes in house price levels. This was in particular the case in the year 1999 when 
Table 1 Summary statistics for house transactions in Amsterdam

\begin{tabular}{|c|c|c|c|c|c|}
\hline Variables & Mean & Std. Dev. & Variables & Mean & Std. Dev. \\
\hline Size & & & Maintenance outside & & \\
\hline $\operatorname{Ln}$ (floor space) $\left(\mathrm{m}^{2}\right)$ & 4,4019 & 0,3931 & Outside: bad & 0,8810 & 0,3238 \\
\hline $\operatorname{Ln}($ lot size $)\left(m^{2}\right)^{1}$ & 4,7056 & 1,1157 & Outside: reasonable & 0,0005 & 0,0230 \\
\hline Volume/floor area (m) & 3,1009 & 6,2673 & Outside: excellent & 0,0041 & 0,0639 \\
\hline Rooms (\#) & 3,2413 & 1,3197 & Garden & & \\
\hline Type & & & Garden & 0,0406 & 0,1973 \\
\hline Detached house & 0,0071 & 0,0840 & * located south of the house & 0,2508 & 0,4335 \\
\hline Semidetached house & 0,0070 & 0,0832 & * nicely designed/well maint & 0,0745 & 0,2626 \\
\hline Corner house & 0,0230 & 0,1499 & Isolation & & \\
\hline Apartment & 0,8788 & 0,3264 & No isolation & 0,0145 & 0,1194 \\
\hline * Entrance at forecourt & 0,1063 & 0,3082 & Fully isolated & 3,2413 & 1,2969 \\
\hline * Entrance at gallery & 0,0071 & 0,0840 & Environment & & \\
\hline Attributes & & & Close to forest & 0,0039 & 0,0626 \\
\hline Balcony & 0,1173 & 0,3218 & Close to water & 0,1313 & 0,3378 \\
\hline Roof terrace & 0,0193 & 0,1377 & Close to park & 0,0508 & 0,2196 \\
\hline Dormer & 0,5018 & 0,5000 & In open space & 0,1329 & 0,3395 \\
\hline Through living room & 0,0984 & 0,2979 & Close to busy road & 0,0382 & 0,1918 \\
\hline Living room en suite & 0,0748 & 0,2631 & Construction period/age & & \\
\hline No central heating & 0,3844 & 0,4865 & Built before 1905 & 0,0357 & 0,1855 \\
\hline Basement & 0,1533 & 0,3603 & * Year of sale -1905 & 22,2107 & 34,1104 \\
\hline Monument & 0,9493 & 0,2195 & Built 1906-1930 & 0,089 & 0,2848 \\
\hline Parking & & & * Year of sale -1930 & 5,2128 & 16,7878 \\
\hline Parking lot & 0,0826 & 0,2753 & Built 1931-1944 & 0,2997 & 0,4582 \\
\hline Carport & 0,0295 & 0,1692 & * Year of sale -1944 & 1,888 & 9,0307 \\
\hline Garage & 0,0309 & 0,1731 & Built 1945-1959 & 0,089 & 0,2848 \\
\hline$*$ indoor & 0,0059 & 0,0768 & * Year of sale -1959 & 3,3626 & 10,1055 \\
\hline * indoor * apartment & 0,0232 & 0,1505 & Built 1960-1970 & 0,0428 & 0,2024 \\
\hline Carport/garage for $\geq 2$ cars & 0,0324 & 0,1770 & * Year of sale -1970 & 0,9463 & 4,6593 \\
\hline Maintenance inside & & & Built 1971-1980 & 0,1037 & 0,3048 \\
\hline Inside: bad & 0,0135 & 0,1154 & * Year of sale -1980 & 1,206 & 4,2627 \\
\hline Inside: reasonable & 0,0024 & 0,0488 & Built 1981-1990 & 0,0382 & 0,1918 \\
\hline Inside: excellent & 0,0188 & 0,1360 & $*$ Year of sale $-1990^{1}$ & 0,5505 & 1,9868 \\
\hline Not filled in & 0,0048 & 0,0690 & $\begin{array}{l}\text { Built } 1991-2000 \\
\quad * \text { Year of sale }-2000^{1}\end{array}$ & 0,0862 & 0,2806 \\
\hline
\end{tabular}

\footnotetext{
${ }^{1}$ Only for observation with positive lot size (apartments excluded)
} 
prices increased by more than one third of the level in the last quarter of 1998, and to a lesser extend after the onset of the crisis when the volatility of the market increased. We will therefore use the quarter as our basic time unit in the empirical work reported below.

After cleaning the data, the total number of observations over the whole period equals 107,235. There is a strong upward trend in the annual number of transactions from 542 in 1985 to 8,300 in 2007 , followed by a downfall to 5,138 in $2012 .{ }^{15}$ The observations refer to 73 postcode areas, but for three of these we have never more than one observation per quarter, which means that we do not observe a ranking of house prices. These postcode areas are not used in the analysis that follows. It happens also for other postcode areas that there is only one observation in one or several quarters. In such cases only the observations for quarter in which at least two observations are present will be used.

\section{Estimation}

\subsection{Estimating the housing services function}

To estimate housing services as a function of housing prices we use the methodology introduced in section 2. Our estimates are based on the rankings of the houses on the basis of transaction prices in a given postcode area and a given quarter. Let $m$ denote a geographical market (postcode area), $t$ a quarter, $n(m t)$ the number of observed transactions in market $m$ and quarter $t$, and rank the observations on the basis of the transaction prices (house 1 has the highest price, house $n(m t)$ the lowest). We specify the housing services function as before (that is: $H=$ $\left.\sum_{k=1}^{K} \beta_{k} X_{k}+\xi\right)$ with $\beta_{1}$ normalized to 1 . The likelihood of the observed ranking in market $m$ at time $t$ is:

\footnotetext{
${ }^{15}$ In the early years of the period this reflects not only the actual increase in the number of transactions, but also the rising share of NVM members in the total number of realtors.
} 


$$
\begin{aligned}
& L_{m t}=\frac{e^{\frac{\left(X_{1 m t}+\sum_{k>1} \beta_{k} X_{1 k}\right)}{\sigma}}}{\sum_{i \geq 1} e^{\frac{\left(X_{1 m t}+\sum_{k>1} \beta_{k} X_{1 k}\right)}{\sigma}}} \frac{e^{\frac{\left(X_{2 m t}+\sum_{k>1} \beta_{k} X_{2 k}\right)}{\sigma}}}{\sum_{i \geq 2} e^{\frac{\left(X_{2 m t}+\sum_{k>1} \beta_{k} X_{2 k}\right)}{\sigma}}} \frac{e^{\frac{\left(X_{3 m t}+\sum_{k>1} \beta_{k} X_{3 k}\right)}{\sigma}}}{\sum_{i \geq 3} e^{\frac{\left(X_{3 m t}+\sum_{k>1} \beta_{k} X_{3 k}\right)}{\sigma}}} \cdots
\end{aligned}
$$

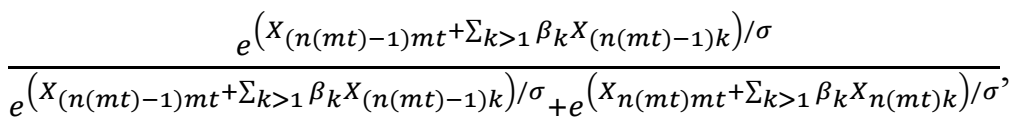

This is identical to (8) except for the notation. A non-trivial likelihood requires $n(m t) \geq 2$. The full likelihood of the whole sample $L$ is the product of the $(m, t)$-specific likelihoods over the set $S$ of combinations of markets and periods in which we have at least two observations:

$$
L=\prod_{\{m, t\} \in S} L_{m t}
$$

We maximize this likelihood by choice of the parameters $\beta_{2} \ldots \beta_{K}$ and $\sigma$ to get estimated values of the housing services $\widehat{H}_{i}=X_{i 1}+\sum_{k}\left(\hat{\beta}_{k}\right) X_{i k}$.

Our approach thus uses quality differences, as indicated by the price ranking, within small spatial areas and periods of three months. Differences in local public goods and in the evolution of the general level of house prices over time can therefore reasonably be expected to have a negligible impact on our estimates. ${ }^{16}$

One of the virtues of the NVM data is that it contains detailed information about housing characteristics. This enables us to use a rich specification for the housing services. We use the natural log of floor space in square meters as the first and arguably most important housing characteristic, for which the coefficient is normalized to 1. Baseline estimation results are reported as model (1) in Table 2.

\footnotetext{
${ }^{16}$ Local public goods would appear in our linear specification of the housing services function as a neighbourhoodspecific constant that cancels in the logit expressions. Movements in the general level of house prices are limited during short periods and the observed price ranking within such a period is dominated by quality differences.
} 
Lot size is less important than to floor area. The volume to floor area ratio gives the average height of the ceiling which is preferred to be high. Given floor area and ceiling height, more rooms add modestly to the quality of the house. ${ }^{17}$

Housing types show the expected hierarchy with detached housing at the top and apartments at the bottom. Terraced housing was used as reference. Much multifamily housing in Amsterdam has an individual entrance at the street, but apartment buildings can have entrances of the individual units in a forecourt or at a gallery, which implies less privacy and is typically less preferred. Housing attributes have the expected signs and magnitudes.

Parking is an important variable in Amsterdam. Having the possibility to park a car on one's parcel implies a substantial increase in housing quality. The presence of a carport does not add much but a garage is definitely more valuable than outside parking. However, the additional value of a garage disappears when it is part of the house. In such cases the garage is often used as a keeping, for instance for bicycles. For apartments this is different as garages are usually in the basement of the building.

The NVM brokers assess the state of maintenance of the inside and outside. Both are categorical variables and if nothing is filled in the data always report one category (reasonable to good) which makes this information somewhat noisy. To deal with this issue we have assumed that this information is missing if this category is reported for maintenance inside and outside. We have grouped the 8 original categories into four and used the category reasonable as our reference. Both variables appear to have a significant impact on housing quality. The estimated coefficient captures the effect of maintenance inside as well as outside of the houses for which this variable is not filled in. It suggests that missing information about the state of maintenance

\footnotetext{
${ }^{17}$ We have experimented with the number of square meters per room to see if there is something like an optimal room size, but the data do not seem to support such a concept.
} 
corresponds usually to housing that is well maintained inside as well as outside. The smaller negative coefficient for bad maintenance outside is unexpected.

The presence of a garden is appreciated. However, its location to the south of the house does not appear to add much quality. On the other hand, a well maintained or nicely designed garden contributes substantially to the production of housing services.

Isolation is reported as a categorical variable. We have distinguished the lowest (no isolation) and the highest (fully isolated) category, using the others as reference. ${ }^{18}$

The location of the house has an important impact on its attractiveness. Locations close to a forest ${ }^{19}$, to water and to a lesser extent close to a park or in open space ${ }^{20}$ have a higher quality. Being close to a busy road is - unsurprisingly - viewed as a disadvantage.

Construction period is available as a categorized variable. In addition to it we include the age of the house, operationalized as the difference between the year of sale and the highest possible year of construction in the relevant class. Houses first sold after 2000 serve as the reference class for the construction period. We find that housing constructed before 1971 is valued less than the reference, as expected, but housing that has been constructed in the 1970s or later is valued more. However, for the impact of age we find the opposite pattern: pre-war housing became more appreciated during the period of observation (1985-2013) but for the younger types of housing there is non-negligible depreciation. The appreciation of pre-war housing is substantial: the order of magnitude is $0.5 \%$ annually. This finding reflects the well-

\footnotetext{
${ }^{18}$ The other categories indicate the number of isolation measures that have been taken. However, these measures are not specified and may therefore differ in importance.

${ }^{19}$ The Amsterdam forest is located to the southwest of the built-up area.

${ }^{20}$ This refers to houses in the rural areas.
} 
Table 2. Estimation results for housing services (Jan 1985 - Jun 2013)

Variables

(1)

(2)

\begin{tabular}{|c|c|c|c|c|c|c|}
\hline \multicolumn{7}{|l|}{ Size } \\
\hline $\operatorname{Ln}$ (floor space) $\left(\mathrm{m}^{2}\right)$ & 1 & - & & 1 & - & \\
\hline $\operatorname{Ln}($ lot size $)\left(\mathrm{m}^{2}\right)$ & 0.0013 & $(.00035)$ & $* * *$ & 0.0013 & $(.00035)$ & $* * *$ \\
\hline Volume/floor area (m) & 0.00042 & $(.00008)$ & $* * *$ & 0.00042 & $(.00008)$ & $* * *$ \\
\hline Rooms (\#) & 0.021 & $(.00051)$ & $* * *$ & 0.021 & $(.00051)$ & $* * *$ \\
\hline \multicolumn{7}{|l|}{ Type } \\
\hline Detached house (ref: standard house) & 0.39 & $(.0080)$ & $* * *$ & 0.39 & $(.0080)$ & $* * *$ \\
\hline $\begin{array}{l}\text { Semidetached house (ref: standard } \\
\text { house) }\end{array}$ & 0.24 & $(.0091)$ & $* * *$ & 0.24 & $(.0091)$ & $* * *$ \\
\hline Corner house (ref: standard house) & 0.055 & $(.0044)$ & $* * *$ & 0.055 & $(.0044)$ & $* * *$ \\
\hline Apartment (ref: standard house) & -0.083 & $(.0029)$ & $* * *$ & -0.083 & $(.0029)$ & $* * *$ \\
\hline * Entrance at forecourt & -0.020 & $(.0020)$ & $* * *$ & -0.020 & $(.0020)$ & $* * *$ \\
\hline * Entrance at gallery & -0.029 & $(.0025)$ & $* * *$ & -0.029 & $(.0025)$ & $* * *$ \\
\hline \multicolumn{7}{|l|}{ Attributes } \\
\hline Balcony & 0.012 & $(.0013)$ & $* * *$ & 0.012 & $(.0013)$ & $* * *$ \\
\hline Roof terrace & 0.071 & $(.0020)$ & $* * *$ & 0.071 & $(.0020)$ & $* * *$ \\
\hline Dormer & 0.021 & $(.0043)$ & $* * *$ & 0.021 & $(.0043)$ & $* * *$ \\
\hline Through living room & 0.010 & $(.0023)$ & $* * *$ & 0.010 & $(.0023)$ & $* * *$ \\
\hline Living room en suite & 0.035 & $(.0023)$ & $* * *$ & 0.035 & $(.0023)$ & $* * *$ \\
\hline No central heating & -0.10 & $(.0017)$ & $* * *$ & -0.10 & $(.0017)$ & $* * *$ \\
\hline Basement & 0.0047 & $(.0053)$ & $* * *$ & 0.0047 & $(.0053)$ & $* * *$ \\
\hline Monument & 0.074 & $(.0039)$ & $* * *$ & 0.074 & $(.0039)$ & $* * *$ \\
\hline \multicolumn{7}{|l|}{ Parking } \\
\hline Parking lot & 0.079 & $(.0035)$ & $* * *$ & 0.079 & $(.0035)$ & $* * *$ \\
\hline Carport & 0.082 & $(.0035)$ & $* * *$ & 0.082 & $(.0035)$ & $* * *$ \\
\hline Garage & 0.14 & $(.0054)$ & $* * *$ & 0.14 & $(.0054)$ & $* * *$ \\
\hline * indoor & -0.0067 & $(.0090)$ & $* * *$ & -0.0067 & $(.0090)$ & $* * *$ \\
\hline * indoor * apartment & 0.039 & $(.0089)$ & $* * *$ & 0.039 & $(.0089)$ & $* * *$ \\
\hline Carport/garage for $\geq 2$ cars & 0.18 & $(.010)$ & $* * *$ & 0.18 & $(.010)$ & $* * *$ \\
\hline \multicolumn{7}{|l|}{ Maintenance } \\
\hline Inside: bad & -0.082 & $(.013)$ & $* * *$ & -0.082 & $(.013)$ & $* * *$ \\
\hline Inside: reasonable & -0.054 & $(.0043)$ & $* * *$ & -0.054 & $(.0043)$ & $* * *$ \\
\hline Inside: excellent & 0.14 & $(.0021)$ & $* * *$ & 0.14 & $(.0021)$ & $* * *$ \\
\hline Outside: bad & -0.047 & $(.021)$ & $* * *$ & -0.047 & $(.021)$ & $* * *$ \\
\hline Outside: reasonable & -0.083 & $(.0078)$ & $* * *$ & -0.083 & $(.0078)$ & $* * *$ \\
\hline Outside: excellent & 0.083 & $(.0030)$ & $* * *$ & 0.083 & $(.0030)$ & $* * *$ \\
\hline Not filled in & 0.10 & $(.010)$ & $* * *$ & 0.10 & $(.010)$ & $* * *$ \\
\hline
\end{tabular}


Table 2. Estimation results for housing services (Jan 1985 - Jun 2013) (cntnd)

Variables

(1)

(2)

\begin{tabular}{|c|c|c|c|c|c|c|}
\hline \multicolumn{7}{|l|}{ Garden } \\
\hline Garden & 0.073 & $(.0017)$ & $* * *$ & 0.073 & $(.0017)$ & $* * *$ \\
\hline * located south of the house & 0.00066 & $(.0024)$ & & 0.00066 & $(.0024)$ & \\
\hline * nicely designed/well maintained & 0.077 & $(.0025)$ & $* * *$ & 0.077 & $(.0025)$ & $* * *$ \\
\hline \multicolumn{7}{|l|}{ Isolation } \\
\hline No isolation & -0.0080 & $(.0013)$ & $* * *$ & -0.0080 & $(.0013)$ & $* * *$ \\
\hline Fully isolated & 0.026 & $(.0019)$ & $* * *$ & 0.026 & $(.0019)$ & $* * *$ \\
\hline \multicolumn{7}{|l|}{ Environment } \\
\hline Close to forest & 0.084 & $(.011)$ & $* * *$ & 0.084 & $(.011)$ & $* * *$ \\
\hline Close to water & 0.083 & $(.0018)$ & $* * *$ & 0.083 & $(.0018)$ & $* * *$ \\
\hline Close to park & 0.032 & $(.0025)$ & $* * *$ & 0.032 & $(.0025)$ & $* * *$ \\
\hline In open space & 0.018 & $(.0018)$ & $* * *$ & 0.018 & $(.0018)$ & $* * *$ \\
\hline Close to busy road & -0.046 & $(.0025)$ & $* * *$ & -0.046 & $(.0025)$ & $* * *$ \\
\hline \multicolumn{7}{|l|}{ Construction period/age } \\
\hline Built before 1905 & -0.53 & $(.089)$ & $* * *$ & -0.53 & $(.089)$ & $* * *$ \\
\hline * Year of sale -1905 & 0.0053 & $(.00090)$ & $* * *$ & 0.0053 & $(.00090)$ & $* * *$ \\
\hline Built 1906-1930 & -0.50 & $(.068)$ & $* * *$ & -0.50 & $(.068)$ & $* * *$ \\
\hline * Year of sale -1930 & 0.0058 & $(.00087)$ & $* * *$ & 0.0058 & $(.00087)$ & $* * *$ \\
\hline Built 1931-1944 & -0.33 & $(.058)$ & $* * *$ & -0.33 & $(.058)$ & $* * *$ \\
\hline * Year of sale -1944 & 0.0043 & $(.00093)$ & $* * *$ & 0.0043 & $(.00093)$ & $* * *$ \\
\hline Built 1945-1959 & -0.10 & $(.051)$ & $*$ & -0.10 & $(.051)$ & $*$ \\
\hline * Year of sale -1959 & -0.0025 & $(.0011)$ & $* * *$ & -0.0025 & $(.0011)$ & $* * *$ \\
\hline Built 1960-1970 & -0.083 & $(.0037)$ & $* *$ & -0.083 & $(.0037)$ & $* *$ \\
\hline * Year of sale -1970 & -0.0059 & $(.0010)$ & $* * *$ & -0.0059 & $(.0010)$ & $* * *$ \\
\hline Built 1971-1980 & 0.11 & $(.030)$ & $* * *$ & 0.11 & $(.030)$ & $* * *$ \\
\hline * Year of sale -1980 & -0.013 & $(.0011)$ & $* * *$ & -0.013 & $(.0011)$ & $* * *$ \\
\hline Built 1981-1990 & 0.069 & $(.017)$ & $* * *$ & 0.069 & $(.017)$ & $* * *$ \\
\hline$*$ Year of sale $-1990^{1}$ & -0.014 & $(.0010)$ & $* * *$ & -0.014 & $(.0010)$ & $* * *$ \\
\hline Built 1991-2000 & 0.038 & $(.0077)$ & $* *$ & 0.038 & $(.0077)$ & $* *$ \\
\hline$*$ Year of sale $-2000^{1}$ & -0.0082 & $(.0011)$ & $* * *$ & -0.0082 & $(.0011)$ & $* * *$ \\
\hline Variance & 0.18 & $(.00037)$ & $* * *$ & & & \\
\hline Postcode-specific variances & & NO & & & YES & \\
\hline Log likelihood & & 183,637 & & & $-167,822$ & \\
\hline Observations & & 101,408 & & & 101,408 & \\
\hline
\end{tabular}


known preferences of Dutch households for housing dating back to the 1920 s and 1930 s.$^{21}$ If we compute the net effect of construction period and aging for the year 2015, we find that our estimates imply that pre-war housing has almost the same quality as housing constructed after 2000 with the same set of characteristics, whereas post-war housing has depreciated considerably. Even for housing constructed in the 1990s a loss in quality of $9 \%$ in 2015 is implied.

A concern one may have with the specification just discussed is that the variation in the unobserved component of the housing services $\xi_{j}$ differs over neighbourhoods. We have therefore also estimated a more elaborate version of the model in which $\sigma$ is $m$-specific for postcode areas in which there are at least 10 observations for at least one quarter in the data. Estimates of this version are presented as model (2). We estimated $60 \sigma_{m}$ parameters. The average of these parameters is 0.169 , the variance 0.0295 . There is a substantial increase in the likelihood. The coefficient estimates of model (2) are very similar to those of model (1).

\subsection{Housing quality}

Our estimated coefficients enable us to compute an approximation to the quality of each house on the basis of its observed characteristics. That is, we compute $\widehat{H}_{i}=X_{i 1}+\sum_{k}\left(\hat{\beta}_{k}\right) X_{i k}$. The average value of our quality measure over all transactions is 4.55 . The standard deviation is on average close to 0.45 . Figure 3 shows that year-to-year changes in both variables are surprisingly limited. The minimum estimated value of the number of housing services in our transaction data is 3.01 , the maximum 7.32 .

\footnotetext{
${ }^{21}$ See Francke and Van der Minne (2016).
} 


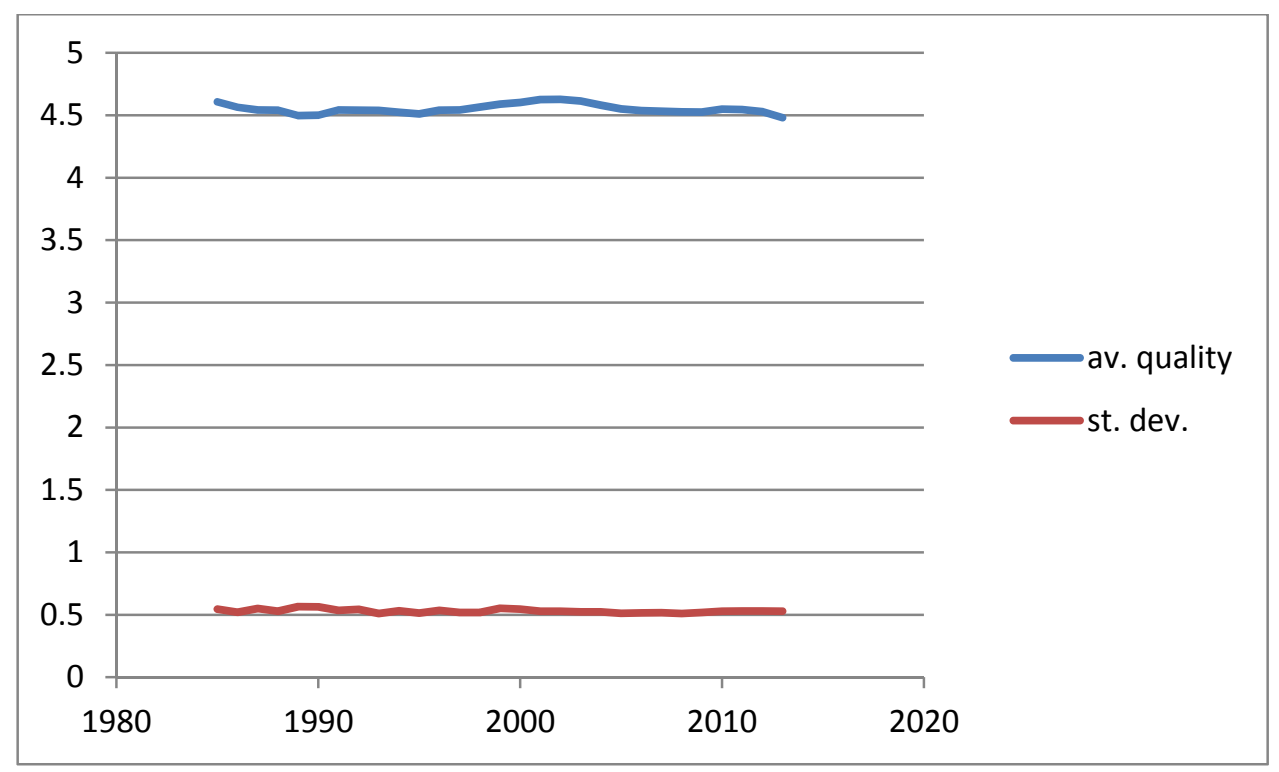

Figure 3 Annual average and standard deviation of housing service per transacted property in Amsterdam

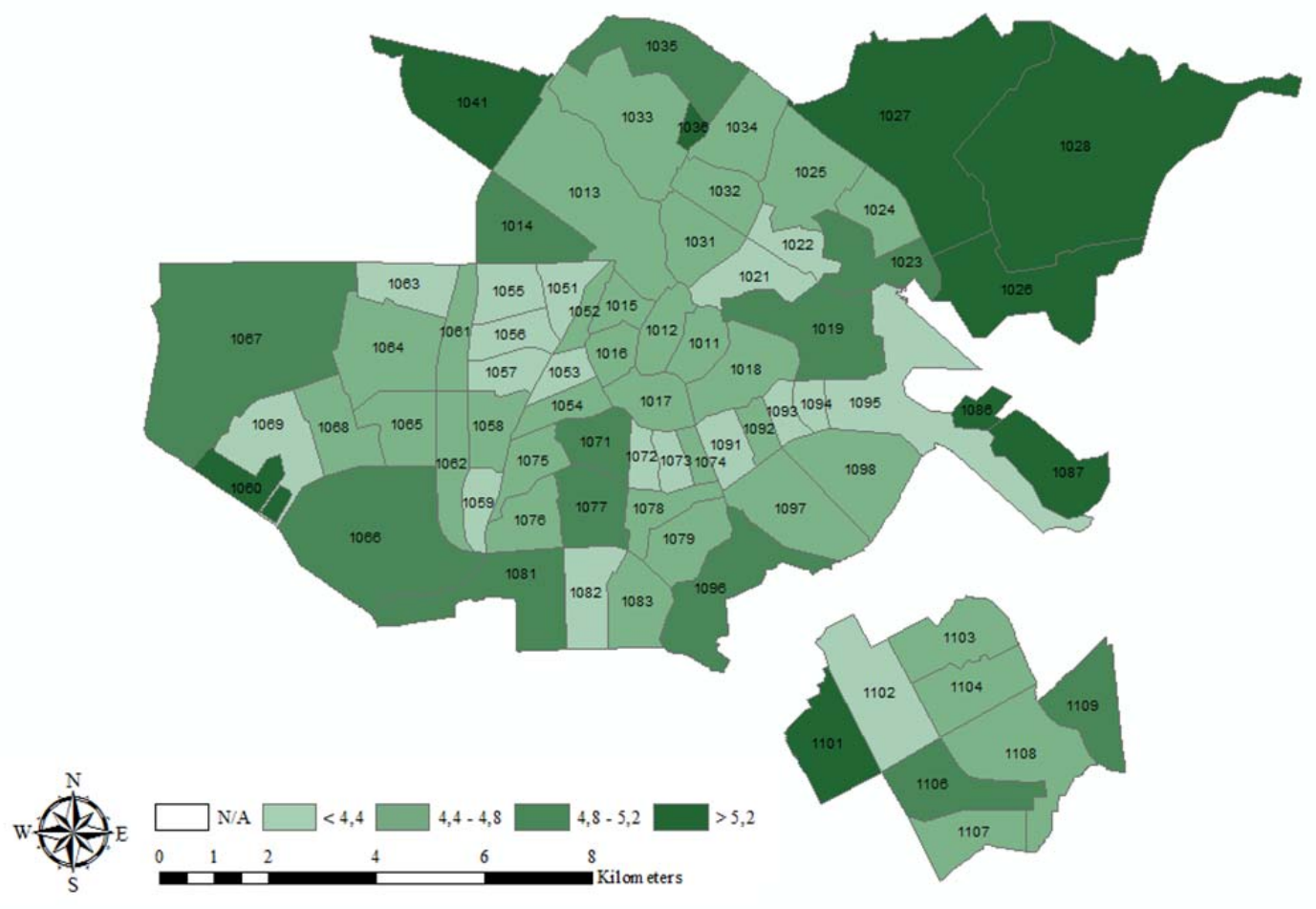

\section{Figure 4 Average quality per postcode area}

Note: the picture is based on an earlier specification and the quality scale is therefore not consistent with the figures mentioned in the text. 
The spatial distribution of quality is shown in Figure 4. Housing of the highest quality is located in the north-west which is an agricultural area, where open space is protected and some former farms have been rebuilt or renovated as luxury housing. The canal belt is in the half circle surrounding postcode areas 1011 and 1012, which is the medieval centre. The canal belt itself is surrounded by a $19^{\text {th }}$ century belt of mainly lower quality housing, with 'old south' (postcode area 1071) as a notable exception.

\subsection{Evolution of house prices over time}

To measure house prices as a function of housing quality in a flexible (non-parametric) way and study their evolution over time, we regressed the house prices on quality, using a local linear quantile approach. The resulting annual housing price functions are shown in Figure 5. Their curvature is always predominantly convex, although parts of the curves are often close to linear and small regions are concave. Over time the convexity tends to become stronger until 2008, while after that year there is no longer a consistent time trend. The curves suggest that luxury housing, as measured by our housing services index, has increased more in value over time than decent housing.

To interpret this information properly, we should note that our estimated measure of housing quality is not unique. It may be interpreted as an ordinal variable, which is to say that any monotone increasing transformation of our quality measure can be interpreted as an alternative measure, while there is no objective reason to prefer one to the other. ${ }^{22}$ The measure that we estimated is (presumably) the one that fitted our econometric model - that assumes an

\footnotetext{
${ }^{22}$ The situation is comparable to that of the utility function in standard microeconomic theory.
} 


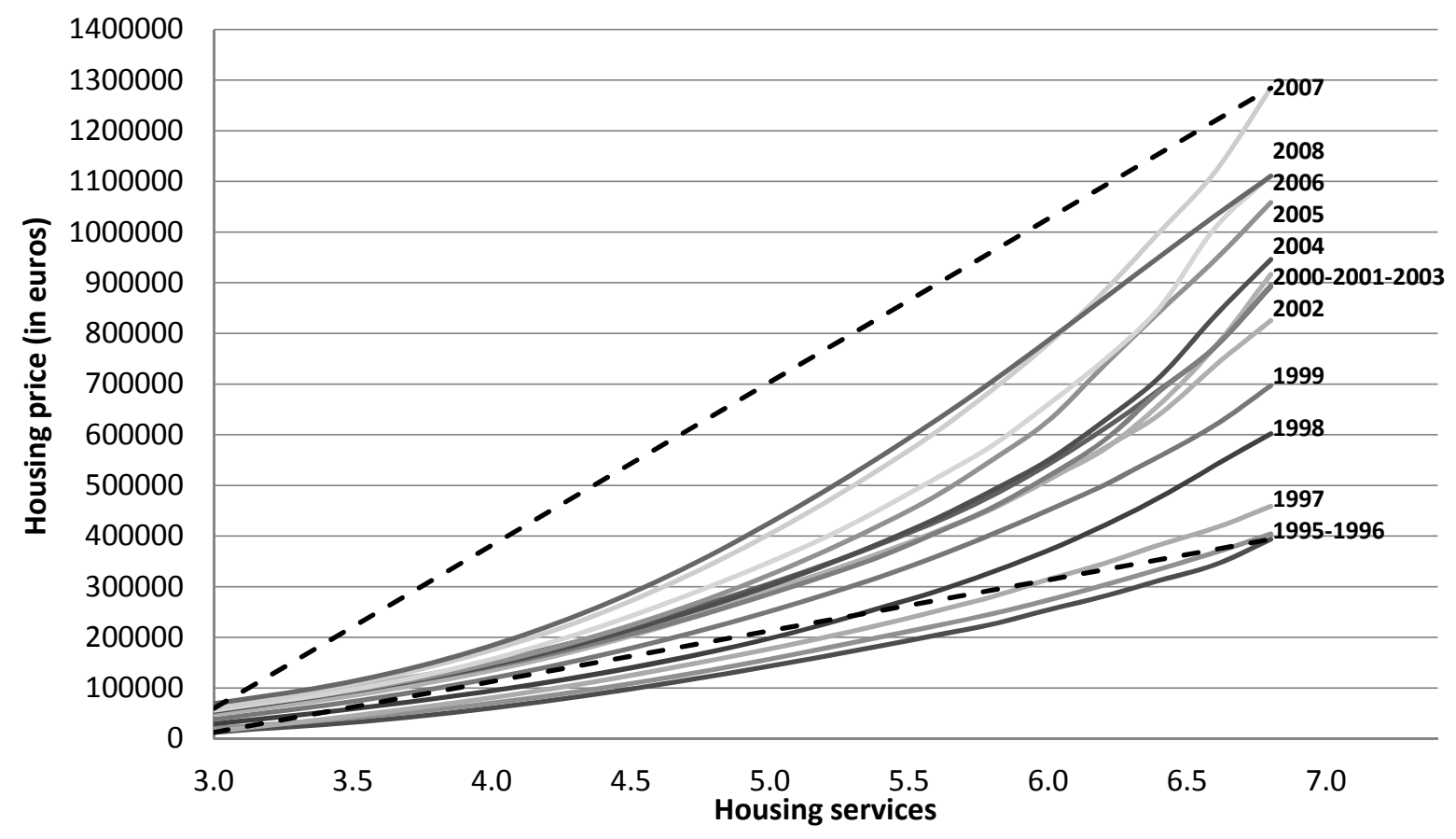

a) $1995-2008$

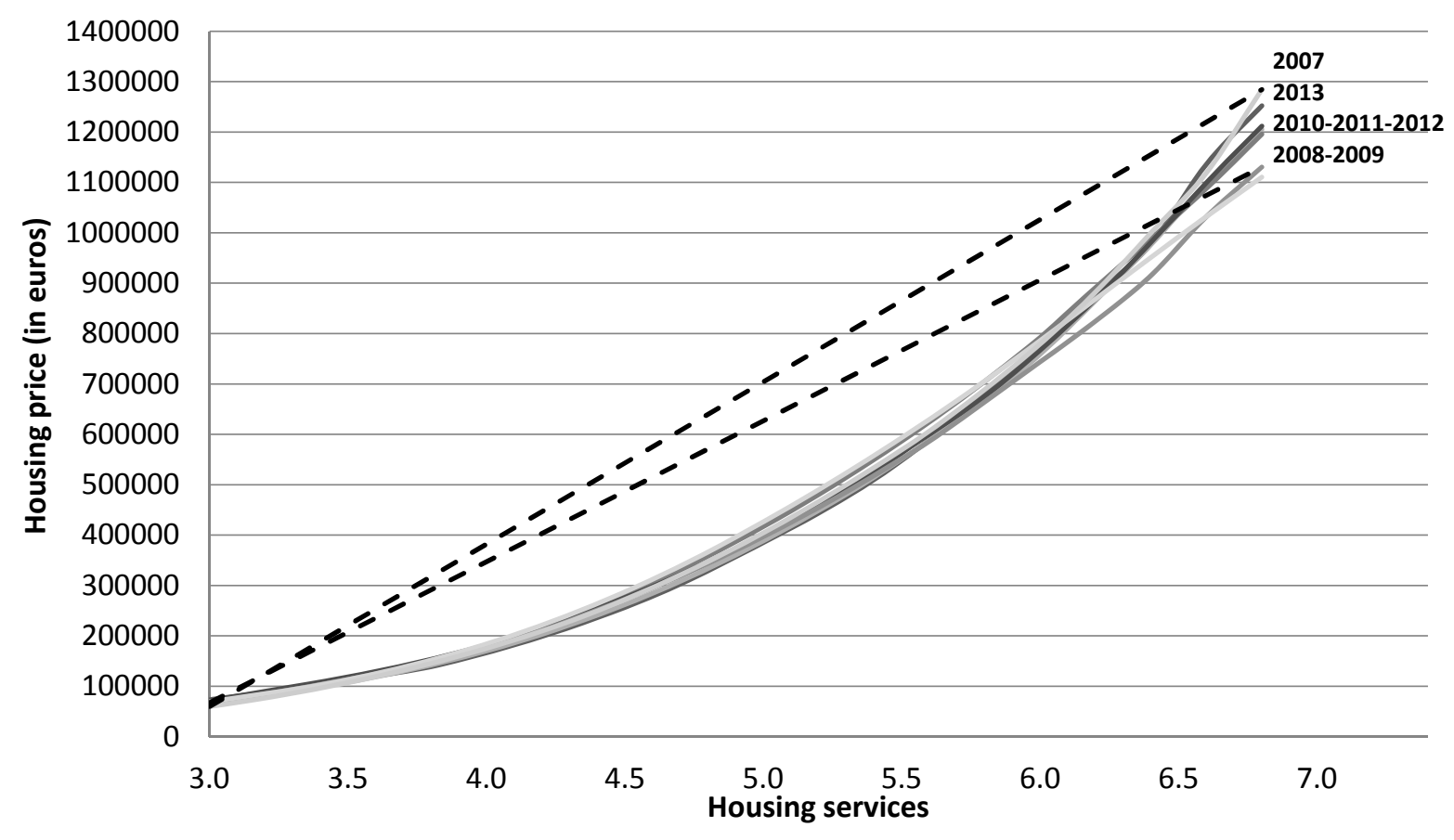

b) $2007-2013$

Figure 5. Annual housing price functions 1995-2013.

The straight dashed lines connect prices at the lowest and highest quality levels. 
additive homoscedastic error term - best, but this provides at best a statistical reason for choosing this particular index.

The implication is that we may stretch or compress our measure of housing services arbitrarily without destroying its interpretation as an index of housing services. Applying such monotonous transformations could obviously result in concave annual curves, or curves that are partly convex and partly concave. It is also possible to choose the index in such a way that it is perfectly linear in one year (but, except coincidentally, not in the others). In the next section we discuss the empirical difference between our model and the original Muth approach in greater depth.

\section{Is the price per unit constant?}

\subsection{A test for a single unit price}

The difference between the hedonic approach (1) and our generalization (5) is that the former imposes proportionality between the prices of houses of different quality in every period, whereas the latter only imposes monotonicity. Since monotonicity has proportionality as a special case, we can in principle test it using our estimates of the generalized Muth model. We already noted that our indicator of housing services is not unique: any monotone transformation of the indicator we estimated is an alternative, equally valid one since it implies the same quality ordering of the houses and it therefore consistent with the same ranking. Our test takes this 'ordinal' character of the housing services index that we estimated into account.

Using the estimated values of our housing services index and the transaction prices, we can non-parametrically estimate the log of the transaction price for any value of the housing services in any period using a local quantile (median) approach. Suppose we do this for two arbitrary values $H_{1}$ and $H_{2}$. If (1) is true, then the difference between the logarithms of the 
estimated prices for these two values of the housing services must be constant over time. To see this, note that we can rewrite (1) as:

$\ln P=\ln \Pi+\ln H$

The unit price $\Pi$ may change over time, but the difference between the logarithms of the prices of houses with $H_{1}$ and $H_{2}$ housing services must always be equal to $\ln \left(H_{1} / H_{2}\right)$.

To check if this is the case we estimated the prices of houses with the average value of housing services (4.55) and the average plus or minus one or two times the standard deviation (0.53). We have estimated the price of these houses in each year separately using local constant quantile regression. ${ }^{23}$ Figure 6 shows the result. The solid lines in that Figure are the estimated prices, and the dotted lines of the same color are the upper and lower bounds of the associated confidence intervals which have been computed on the basis of Fan and Liu (2016). ${ }^{24}$ For the lowest quality houses we were unable to carry out the quantile regression in the early years 1985 and 1986 (probably due to the limited number of observations). The confidence intervals are relatively wide for the early years and for the highest and lowest quality houses, which is related to the relatively small numbers of observations. All the solid lines show roughly the same curvature but they are not exactly parallel to each other.

To test the hypothesis of a constant price per unit we present, in Figure 7, the difference $\Delta$ LnPrice between the estimated prices of houses with quality that differs one or two standard deviations from the average and the estimated prices of houses with the average quality. That is, for each year we compute the difference between the estimated price of housing with quality equal to the average plus two standard deviations $(H=4.55+2 * 0.53)$ and the estimated price of

\footnotetext{
${ }^{23}$ We used normal weights centred at the relevant quality level and used Silverman's rule of thumb to determine the bandwidth (which is usually close to 0.10 ).

${ }^{24}$ See Appendix $\mathrm{C}$ for details about the computation of the confidence intervals.
} 


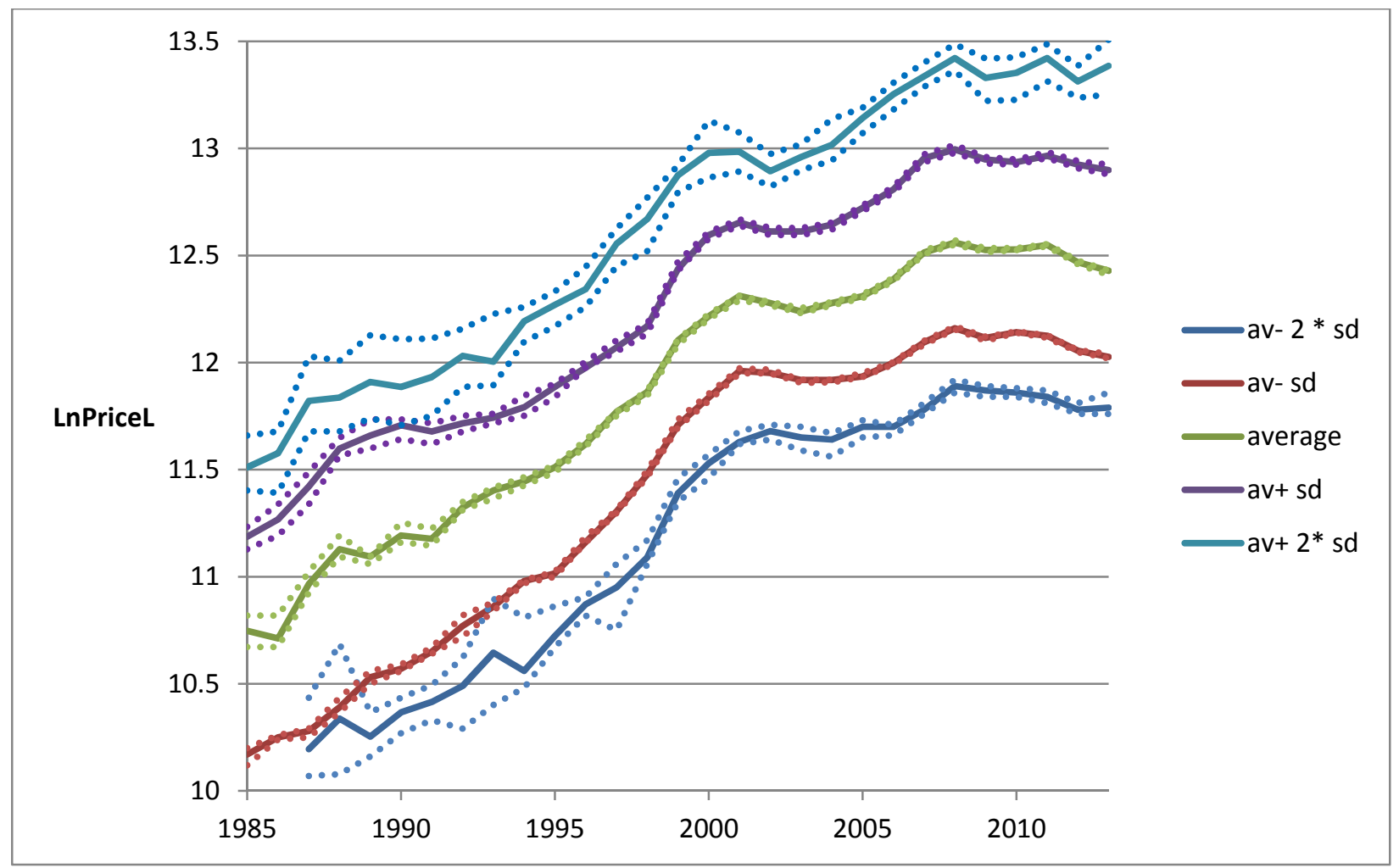

Figure 6 Estimated house prices for different quality levels January 1985 - June 2013

housing with average quality $(H=4.55)$ and computed the associated confidence interval. ${ }^{25}$ The result is the upper line in Figure 7, labelled $(\mathrm{av}+2 * \mathrm{sd})$-av and its confidence interval. The hypothesis that the unit price is constant for a monotonic transformation of our index of housing services cannot be rejected if there exists a horizontal line that remains within the confidence interval associated with this line. This is not the case for this comparison. The maximum value of the lower bound exceeds the minimum value of the upper bound. This means that the hypothesis of a constant unit price is violated by this comparison.

The other lines in Figure 7 are constructed similarly. None of these lines are compatible with a constant unit price. For three of the four comparisons shown (the exception are houses of the highest quality level) there appears to be convergence in the first part of the period considered ${ }^{25}$ See Appendix $\mathrm{C}$ for the details. 


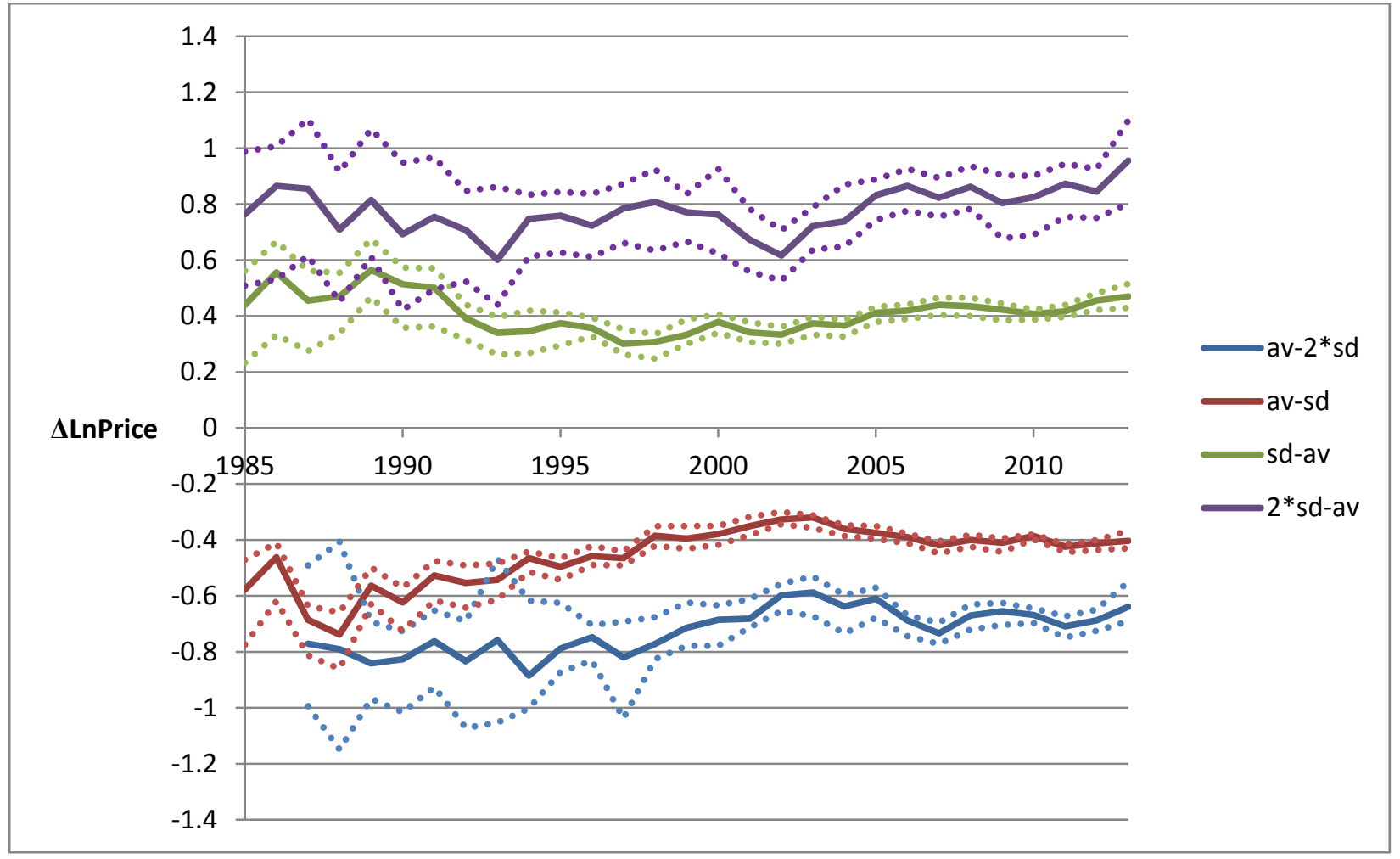

Figure 7 Estimated price differences between above and below average quality houses with average quality houses

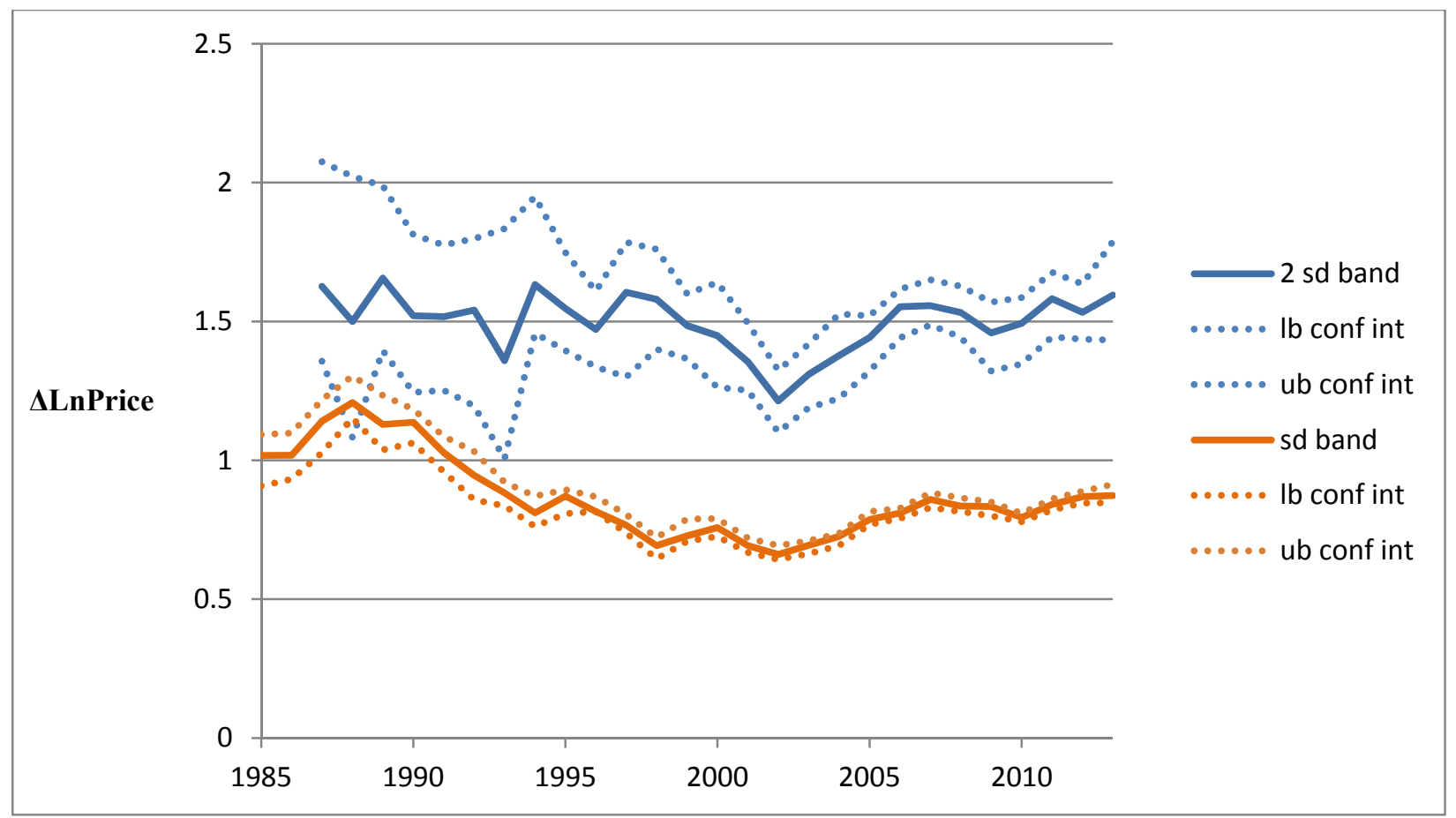

Figure 8 Estimated price differences between higher and lower than average quality houses 
since the lines get closer to the horizontal axis. In the later year there is divergence, but the turning point differs for the various comparisons made.

There is no reason to consider only comparisons with houses of average quality. Figure 8 shows the results if houses with above average quality are compared with those below average quality. In both cases the constant unit price is rejected. This rejection is clearest if the deviation from the average is one standard deviation, but despite the much wider confidence intervals, it is also the case if the difference with the mean equals two standard deviations.

\section{Including area effects}

One concern one may have with the analysis just presented is that the results may have been affected by neighborhood effects. If house prices differ over neighbourhoods due to differences in local amenities and the distribution of the transactions over these neighbourhoods changes over time, this will result in differences in estimated prices at a given quality that may still be consistent with a constant unit price of housing services within each neighbourhood. This phenomenon will especially be relevant if the change in the spatial distribution of the transactions is related to the quality level. To take this possibility into account, we have carried out a weighted quantile regression with area fixed effects for the five quality levels distinguished earlier.

We distinguish 7 areas, that coincide with popular notions of the parts of the city that are mutually different: ${ }^{26}$ the Centre (1) including the canal belt, North (2) across the river IJ, West (3) with mainly 19th and early 20th century housing, New-west (4) farther to the west with mainly post-war housing, South (5) with predominantly 19th and early 20th century housing, East (6) which has areas from the same periods as well as some modern (post 1990) parts (IJburg) and South-east (7) which dates back to the 1960s and 1970s and includes the Bijlmer area. New-west

\footnotetext{
${ }^{26}$ The areas we use are administrative units called 'stadsdelen.'
} 
and South-east are generally perceived to be the least attractive areas of the city. The modern parts of East, which were constructed in the 1990s and later, are higher appreciated.

In the previous section we estimated the price of houses of a given quality level for each year, pooling observations for all areas within the city. We now want to allow for area fixed effects, that is, for differences in price levels between areas that are constant over time. Such constant area fixed effects can only be estimated if we pool observations for different years. We therefore use weighted regressions, with the weights centered at the relevant quality level, on all observations. This gives a consistent series of annual house prices that refer to the whole city except for an area-specific shift in the log price.

The regression equation is:

$\ln p_{i a t}=\alpha+\sum_{t=1986}^{2013} \beta_{t} d_{i t}+\sum_{a=1}^{6} \gamma_{a} d_{i a}+\varepsilon_{i a t}$.

To estimate it, we use weighted quantile (median) regression, with the weights centred on the quality level in which we are interested. These are the same as those used in the previous section. We use all observations in each regression to make sure that the neighbourhood effects are identical in each year. The estimated equation predicts the price of a house with a predetermined quality level as the sum of the constant $\alpha$, a time dummy $\beta_{t}$ (except for observation referring to 1985) and an area dummy $\gamma_{a}$ (except for observations referring to area 7, South-East).

Estimation of (15) gives us separate estimates of the $\gamma_{a}$ 's for each quality level considered. This provides an interesting possibility to test another aspect of the constant unit price hypothesis. This model assumes that per market there is only one unit price. The implication is that houses of similar quality observed in different geographical markets must always have the same price ratio. The coefficients for the area-dummies should thus be independent of the quality level considered. Put differently: the coefficients for the fixed effect of 
a given area estimated for different quality levels should not significantly differ from each other. We will investigate the validity of this property below.

The weights used in the quantile regressions are normal and centred at the quality level that we study (e.g. average plus two standard deviations) with bandwidths determined by Silverman's rule of thumb. The regression equation has fixed-effect dummies for all years except one and six neighbourhoods (we used South-East as the reference). We used standard bootstrap techniques to compute standard errors.

In Figure 9 we show the evolution of the price of houses with quality one standard deviation below or above the median relative to 1985 and the boundaries of the associated confidence intervals. The figure shows the evolution of the log house price index as implied by the values of the estimated $\beta_{t}$ 's for quality levels one standard deviation below the median (the blue line) and one standard deviation above the median (the red line) and the associated confidence intervals as implied by their standard errors. It is clear from the picture that initially the price of the higher quality housing increased faster, relative to its 1985 value than that of higher quality housing, but after the year 1995 the roles became decisively reversed and from 2000 onwards the price index for higher quality housing is significantly lower than that of low quality housing. The financial crisis and the following recession did not change this picture. We thus find again a clear rejection of the unit price hypothesis.

The pattern is similar to that of the sd-band shown in Figure 8 which compares the same quality levels without correcting for area fixed effects. That picture also shows initial divergence followed by convergence. In Figure 8 the rejection of the unit price hypothesis is already clear before 1995. This may be related to the absence of neighborhood dummies in the underlying estimates. 
Figure 9 Estimated log prices of houses with quality one sd's below or above the median relative to the 1985 prices.

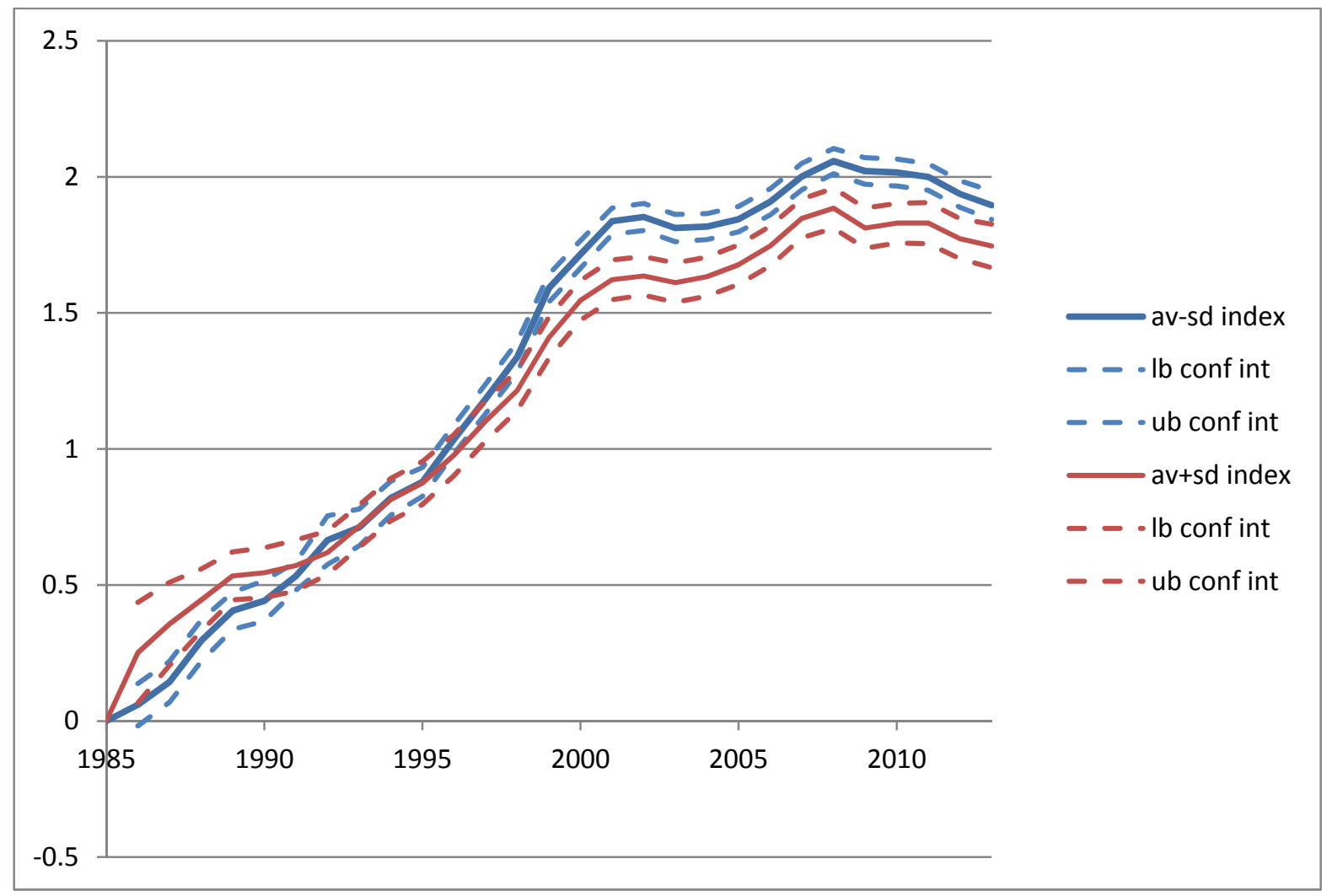

The results of estimating the area fixed effects are shown in Figure 10. The diagrams show the point estimates and the associated confidence intervals for 5 quality levels referring to median-2sd, median-sd,..., median $+2 \mathrm{sd}$. The constant unit price hypothesis is accepted when the confidence intervals of the estimates for the various quality levels considered overlap. However, we find that for each area the hypothesis of a constant unit price is rejected. The pattern shown by the various estimates is interesting. The Centre is known as an expensive part of Amsterdam, and our estimates show that this is especially true for the high quality houses. North is known for its cheap housing, and the diagram shows that this is especially true for high quality housing. A similar remark can be made for New West, another less expensive area. South is a posh area that 

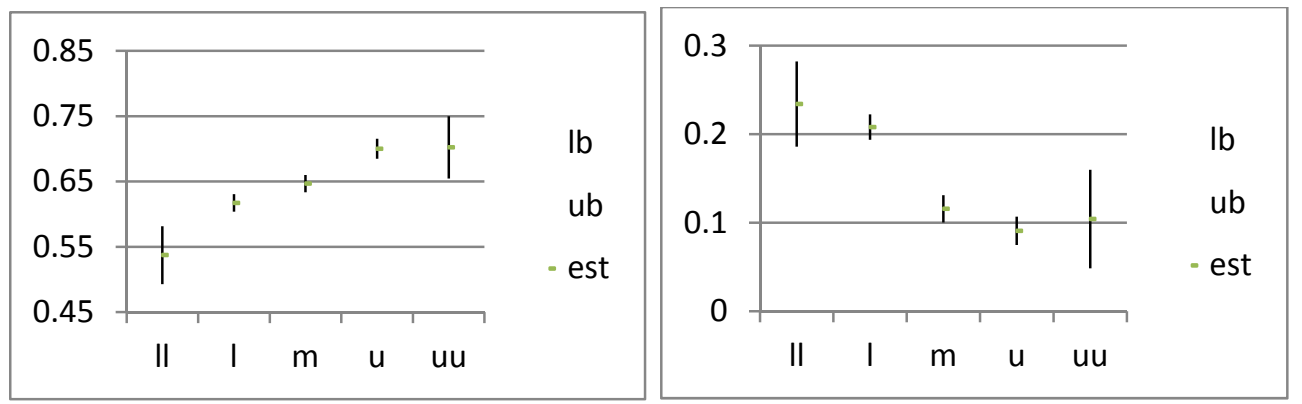
a) Centre
b) North
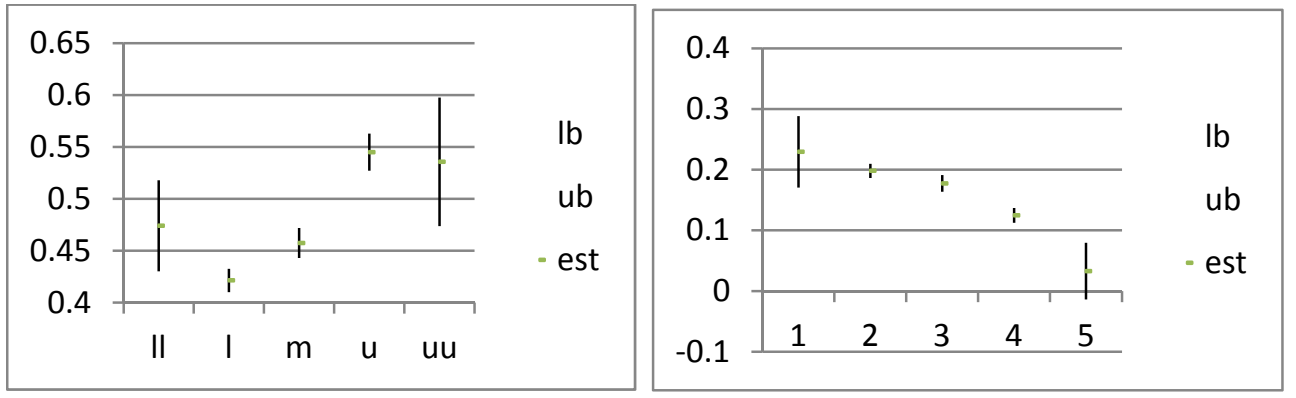

c) West

d) New West
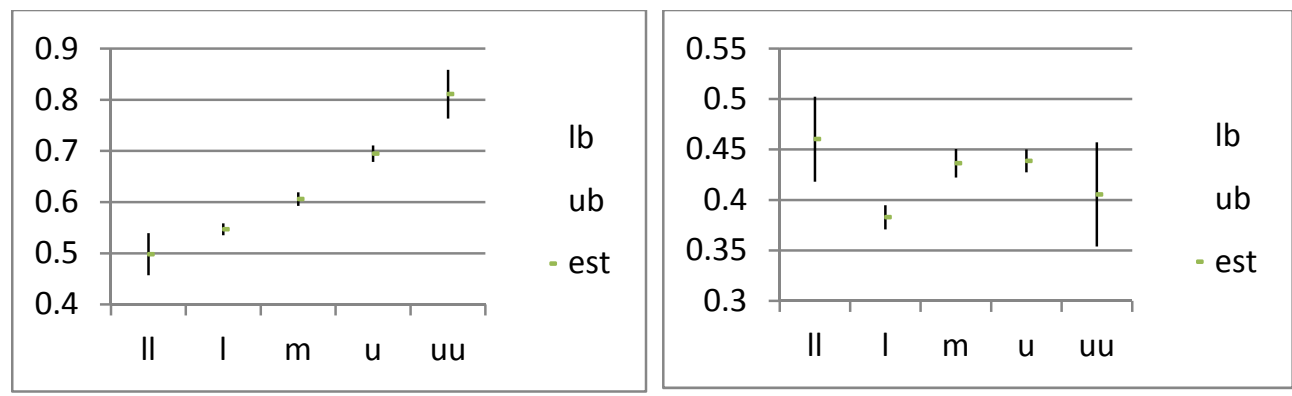

e) South

f) East

\section{Figure 10 Estimated area fixed effects per quality level}

$\mathrm{ll}=$ median-2sd, $\mathrm{l}=$ median-sd, $\mathrm{m}=$ media, $\mathrm{u}=$ median $+\mathrm{sd}$, $\mathrm{uu}=$ median $+2 \mathrm{sd}$.

shows the same pattern as Centre. For West and East we find a non-monotonic pattern that is less easy to interpret. 
It is noteworthy that the quality-dependent fixed effects shown in Figure 10 are incompatible with a hedonic price function with dummies for each area-period combination. Such a specification allows the unit price of housing to develop independently over time for each postcode area, and it is therefore quite flexible. However, it still imposes that the local trend is independent of quality.

The findings of the present section thus provide further evidence against the constant unit price model. That model does not only fail to describe the evolution of house prices over time, but is also inadequate in its description of the relationship between quality and price in different areas.

\section{Conclusion}

This paper has developed a methodology for estimating the quality of housing as a onedimensional indicator - the housing services proposed by Muth (1960) - without imposing the conventional assumption of a constant unit price. The relevance of this approach was strongly suggested by the numerous existing examples of different price developments for segments of the housing market discussed in the introductory section. Our approach stays close to Muth's original idea but avoids the assumption of perfect malleability of housing services. If the supply of houses with a given number of housing services (quality) is fixed in the short run, there is no reason to expect the price per unit of housing services to be equal across the whole quality spectrum.

The methodology we propose separates the estimation of the housing services from the estimation of the price as a function of housing services. Estimation of the housing quality index is based on the observation that in our generalized Muth model the ranking of house prices reflects the ranking of the housing qualities. We then use a logit-based specification for the probability that a particular ranking will be observed to estimate our index for housing services, 
using only information about transactions in the same postcode area in a given quarter. Next, we use the estimated housing quality to recover the housing price as a function of quality.

We developed a test for the property of a constant unit price of housing that does not depend on a particular version of the housing services index. The test requires that the difference in the log price associated with a given difference in quality must be constant over time. We find that our data reject this property and hence the constant unit price of the standard model.

When neighbourhood fixed effects are introduced, we find that they also depend on quality levels, which constitutes a second rejection of the constant unit price hypothesis. In particular, we find that two of the most popular areas, Centre and South, have neighbourhood effects that increase with quality, while in the less attractive North and New-West they decrease with quality.

The approach developed in this paper could be helpful in analyzing housing markets in other areas for which diverging house prices have been reported, see the references in the introductory section. See (Mulalic, Rasmussen, Rouwendal, \& Woltmann, 2017) for an application to Copenhagen.

One limitation of the analysis presented in this paper is that we have to use relatively strong functional form assumptions to be able to estimate the housing price index. One way to relax them would be to further develop the quadratic programming approach discussed in the appendix. Another possibility might be to use the results of De Palma and Kilani (2013) to derive expressions for the probability of observing a particular ranking that use less restrictive assumptions.

\section{References}


Arnott, R. (1987) Economic theory and housing. Chapter 24 in: E.S. Mills (ed) Handbook of Regional and Urban Economics. Elsevier.

Beggs, S., S. Cardell and J. Hausman (1981) Assessing the potential demand for electric cars. Journal of Econometrics, 17, 1-19.

De Palma, A. and K. Kilani (2013) Lower-order choices in random utility models. Working paper.

Epple, D., L. Quinteiro and H. Sieg (2015) A new approach to estimating hedonic equilibrium models for metropolitan housing markets. Working paper.

Fan, Y. and R. Liu (2017) A direct approach to inference in nonparametric and semiparametric quantile models. Journal of Econometrics, 191 (2016), 196-216.

Francke, M.K. and A.M. van der Minne (2016) Land, structure and depreciation. Real Estate Economics.

Guerrieri, V., D. Hartley and E. Hurst (2013) Endogenous gentrification and housing price dynamics. Journal of Public Economics, 100, 45-60.

Horowitz, J.L. and W. Haerdle (1996) Direct semiparametric estimation of single-index models with disrete covariates. Journal of the American Statistical Association, 91, 1632-1640.

Ichimura, H. (1993) Semiparametric least squares (SLS) and weighted SLS estimation of singleindex models. Journal of Econometrics, 58, 71-120.

Klein, R.W. and R.H. Spady (1993) An efficient semiparametric estimator for binary response models. Ecnometrica, 61, 387-421.

Koenker, R. (2005) Quantile regression. Cambridge.

Landvoigt, T, M. Piazzesi and M. Schneider (2012) The housing market(s) of San Diego. NBER working paper 17723.

Liu, C.H., A. Nowak, and S.S. Rosenthal (2014) Bubbles, post-crash dynamics and the housing market. Working paper.

McMillen, D. (2008) Changes in the distribution of house prices over time: Structural characteristics, neighborhood, or coefficients? Journal of Urban Economics, 64, 573-589.

Muth (1960) The demand for non-farm housing. In: A.C. Harberger (ed.) The Demand for Durable Goods, Chicago, 29-96.

Olsen, E.E. (187) The demand and supply of housing service: A critical review of the empirical literature. Chapter 25 in: E.S. Mills (ed) Handbook of Regional and Urban Economics. Elsevier.

Rouwendal, J. (1998) On housing services. Journal of Housing Economics, 7, 218-242.

Zietz, J., E.N. Zietz and G.S. Sirmans (2008) Determinants of House Prices: A Quantile Regression Approach. Journal of Real Estate Finance and Economics, 37, 317-333. 


\section{Appendix A. A least squares approach to the estimation of housing services}

Assuming a linear-in-parameters specification of housing services, and setting the coefficient for the first housing attribute equal to 1 , we can write:

$H_{i}=x_{1 i}+\sum_{k=2}^{K} \beta_{k} x_{k i}+\xi_{i}$

Without loss of generality we can choose the index $i$ so that it reflects the ranking of the houses based on their prices. That is, we always have: $P_{i}>P_{i+1}$.

We want to find coefficients $\beta_{k}$ that support this ranking as close as possible. To find them, we propose a least squares approach. We minimize:

$S=\frac{1}{2} \sum_{i} \xi_{i}^{2}$

subject to the constraints implied by the observed ranking:

$x_{1 i}+\sum_{k=2}^{K} \beta_{k} x_{k i}+\xi_{i}>x_{1 i+1}+\sum_{k=2}^{K} \beta_{k} x_{k i+1}+\xi_{i+1}$ for all $i=1 \ldots I-1$.

This is a quadratic programming problem with inequality constraints. The associated Lagrangian is:

$L=\sum_{i=1}^{I} \xi_{i}^{2}+\sum_{i=1}^{I-1} \lambda_{i}\left(\Delta x_{1 i}+\sum_{k=2}^{K} \beta_{k} \Delta x_{k i}+\Delta \xi_{i}\right)$

where $\Delta y_{i}=y_{i}-y_{i+1}$. The first-order conditions are:

$\xi_{1}=\lambda_{1}, \quad \xi_{i}=-\lambda_{i-1}+\lambda_{i}, i=2 \ldots I-1, \quad \xi_{I}=-\lambda_{I-1}$,

$\sum_{i=1}^{I-1} \lambda_{i} \Delta x_{k i}=0, k=2 \ldots K$,

$\lambda_{i}\left(\Delta x_{1 i}+\sum_{k=2}^{K} \beta_{k} \Delta x_{k i}+\Delta \xi_{i}\right)=0, \lambda_{i}>0, \Delta x_{1 i}+\sum_{k=2}^{K} \beta_{k} \Delta x_{k i}+\Delta \xi_{i}, \quad i=1 \ldots I-1$.

We can easily derive:

$\lambda_{i}=\sum_{j=1}^{i} \xi_{i}, \quad i=1 \ldots I-1$

$\Delta \xi_{1}=2 \lambda_{1}-\lambda_{2}, \Delta \xi_{i}=-\lambda_{i-1}+2 \lambda_{i}-\lambda_{i+1}, i=2 \ldots I-2$,

$\xi_{i+1} \leq \xi_{i}+\Delta \widehat{H}_{i} \quad i=1 \ldots I-1$, where $\Delta \widehat{H}_{i}=\Delta x_{1 i}+\sum_{k=2}^{K} \beta_{k} \Delta x_{k i}$ 
Easily applicable solution methods for this problem do not seem to exist.

\section{Appendix B. Comparison with hedonic price function}

To be able to compare our approach with the standard hedonic, we have also estimated (4), using the same specification of the housing services function. The results are presented in Table 3. Model (1) is a specification with year dummies and neighbourhood fixed effects. Model (2) has fixed effects for each combination of neighbourhood and quarter and is therefore close to the model we estimated on the basis of the price ranking.

As expected, the results of the hedonic price function are qualitatively similar to those of the ranking analysis in Table 2: the signs and the relative values of the coefficients are the same in almost all cases. However, the values of the coefficients can differ substantially.

The remarks that follow are based on a comparison in which we have scaled the coefficients of the hedonic equation so that the coefficient for floor space equals $1 .{ }^{27}$ For instance, value attached to parcel size and height relative to floor space is much larger according to the hedonic function (1), while the number of rooms is appreciated less. The effect of a basement is twice as high in the hedonic regression. The coefficient for a beautiful (well designed and/or well maintained) garden is nine times as high. The negative impact of the house being constructed in the three earliest periods is more than twice as large, as is the positive effect of the interaction between age and these construction periods.

It is remarkable that the differences with the housing services equation become in some cases much larger if we switch to specification (2), which one expects to be closer to the housing services equation because of its richer set of controls. This happens, for instance with the coefficient for the parking lot, which decreases by a factor 10 in comparison to (1), where the

\footnotetext{
${ }^{27}$ That is, we divided each coefficient by that for floor space.
} 
Table Estimation results for hedonic price functions (Jan 1985 - Jun 2013)

Variables

(1)

(2)

\begin{tabular}{|c|c|c|c|c|c|c|}
\hline \multicolumn{7}{|l|}{ Size } \\
\hline $\operatorname{Ln}($ floor space $)\left(\mathrm{m}^{2}\right)$ & 0.77 & .0022 & $* * *$ & .85 & .0027 & $* * *$ \\
\hline $\operatorname{Ln}($ lot size $)\left(\mathrm{m}^{2}\right)$ & 0.0017 & .00035 & $* * *$ & .0013 & .00045 & $* * *$ \\
\hline Volume/floor area (m) & 0.00059 & .00008 & $* * *$ & .00077 & .00011 & $* * *$ \\
\hline Rooms (\#) & 0.010 & .00059 & $* * *$ & .0056 & .00075 & $* * *$ \\
\hline \multicolumn{7}{|l|}{ Type } \\
\hline Detached house & 0.34 & .0068 & $* * *$ & .24 & .0082 & $* * *$ \\
\hline Semidetached house & 0.17 & .0067 & $* * *$ & .078 & .0084 & $* * *$ \\
\hline Corner house & 0.036 & .0039 & $* * *$ & -.0069 & .0049 & $* * *$ \\
\hline Apartment & -0.034 & .0028 & $* * *$ & .10 & .0034 & $* * *$ \\
\hline * Entrance at forecourt & -0.019 & .0020 & $* * *$ & -.033 & .0025 & $* * *$ \\
\hline * Entrance at gallery & -0.033 & .0022 & $* * *$ & -.097 & .0028 & $* * *$ \\
\hline \multicolumn{7}{|l|}{ Attributes } \\
\hline Balcony & 0.0036 & .0012 & $* * *$ & .013 & .0015 & $* * *$ \\
\hline Roof terrace & 0.048 & .0018 & & .065 & .0023 & $* * *$ \\
\hline Dormer & -0.0032 & .0038 & $* * *$ & -.018 & .0048 & $* * *$ \\
\hline$\geq 2$ Toilets & 0.0011 & .0016 & $* * *$ & -.0097 & .0021 & $* * *$ \\
\hline$\geq 2$ Bathrooms & 0.037 & .0028 & $* * *$ & .073 & .0035 & $* * *$ \\
\hline Through living room & 0.0051 & .0021 & $* *$ & .017 & .0026 & $* * *$ \\
\hline Living room en suite & 0.031 & .0022 & $* * *$ & .084 & .0028 & $* * *$ \\
\hline No central heating & -0.069 & .0017 & $* * *$ & -.076 & .0021 & $* * *$ \\
\hline Basement & 0.076 & .0045 & $* * *$ & .13 & .0057 & $* * *$ \\
\hline Monument & 0.074 & .0032 & $* * *$ & .064 & .0040 & $* * *$ \\
\hline \multicolumn{7}{|l|}{ Parking } \\
\hline Parking lot & 0.063 & .0036 & $* * *$ & .0068 & .0043 & $* * *$ \\
\hline Carport & 0.080 & .0034 & $* * *$ & .065 & .0043 & $* * *$ \\
\hline Garage & 0.14 & .0047 & $* * *$ & .14 & .0060 & $* * *$ \\
\hline * indoor & -0.099 & .0068 & $* * *$ & -.089 & .0086 & $* * *$ \\
\hline * indoor * apartment & 0.078 & .0071 & $* * *$ & .044 & .0090 & $* * *$ \\
\hline Carport/garage for $\geq 2$ cars & 0.16 & .0076 & $* * *$ & .17 & .0097 & $* * *$ \\
\hline \multicolumn{7}{|l|}{ Maintenance } \\
\hline Inside: bad & -0.033 & .011 & $* * *$ & -.032 & .014 & $* *$ \\
\hline Inside: reasonable & -0.028 & .0043 & $* * *$ & -.017 & .0055 & $* * *$ \\
\hline Inside: excellent & 0.089 & .0020 & $* * *$ & .085 & .0025 & $* * *$ \\
\hline Outside: bad & -0.036 & .023 & & -.013 & .029 & \\
\hline Outside: reasonable & -0.050 & .0080 & $* * *$ & -.044 & .010 & $* * *$ \\
\hline Outside: excellent & 0.071 & .0028 & $* * *$ & .069 & .0036 & $* * *$ \\
\hline Not filled in & 0.095 & .0085 & $* * *$ & .081 & .011 & $* * *$ \\
\hline
\end{tabular}


Table Estimation results for hedonic price functions (Jan 1985 - Jun 2013) (cntnd)

Variables

(2)

\begin{tabular}{|c|c|c|c|c|c|c|}
\hline \multicolumn{7}{|l|}{ Garden } \\
\hline Garden & 0.047 & .0017 & $* * *$ & .047 & .0022 & $* * *$ \\
\hline * located south of the house & 0.0013 & .0023 & & .0027 & .0029 & \\
\hline * nicely designed/well maintained & 0.056 & .0022 & $* * *$ & .065 & .0028 & $* * *$ \\
\hline \multicolumn{7}{|l|}{ Isolation } \\
\hline No isolation & -0.0059 & .0013 & $* * *$ & .025 & .0016 & $* * *$ \\
\hline Fully isolated & 0.011 & .0019 & $* * *$ & -.0027 & .0024 & $* * *$ \\
\hline \multicolumn{7}{|l|}{ Environment } \\
\hline Close to forest & 0.072 & .0088 & $* * *$ & .061 & .011 & $* * *$ \\
\hline Close to water & 0.063 & .0018 & $* * *$ & .065 & .0022 & $* * *$ \\
\hline Close to park & 0.034 & .0026 & $* * *$ & .0045 & .0033 & $* * *$ \\
\hline In open space & 0.011 & .0017 & $* * *$ & -.017 & .0021 & $* * *$ \\
\hline Close to busy road & -0.036 & .0028 & $* * *$ & -.018 & .0036 & $* * *$ \\
\hline \multicolumn{7}{|l|}{ Construction period/age } \\
\hline Built before 1905 & -0.98 & .10 & $* * *$ & -1.89 & .12 & $* * *$ \\
\hline * Year of sale - 1905 & 0.0097 & .00098 & $* * *$ & .020 & .0012 & $* * *$ \\
\hline Built 1906-1930 & -0.93 & .076 & $* * *$ & -1.22 & .096 & $* * *$ \\
\hline * Year of sale -1930 & 0.012 & .00097 & $* * *$ & .017 & .0012 & $* * *$ \\
\hline Built 1931-1944 & -0.65 & .064 & $* * *$ & -.87 & .081 & $* * *$ \\
\hline * Year of sale -1944 & 0.0098 & .001 & $* * *$ & .014 & .0012 & $* * *$ \\
\hline Built 1945-1959 & -0.12 & .050 & & -.27 & .064 & $* * *$ \\
\hline * Year of sale -1959 & -0.0006 & .0010 & & .0027 & .0013 & $* *$ \\
\hline Built 1960-1970 & -0.026 & .038 & & -.51 & .048 & $* * *$ \\
\hline * Year of sale -1970 & -0.0048 & .0010 & $* * *$ & .0058 & .0013 & $* * *$ \\
\hline Built 1971-1980 & 0.0037 & .029 & & -.37 & .037 & $* * *$ \\
\hline$*$ Year of sale -1980 & -0.0058 & .0010 & $* * *$ & .0039 & .0013 & $* * *$ \\
\hline Built 1981-1990 & 0.044 & .018 & $* *$ & -.093 & .023 & $* * *$ \\
\hline$*$ Year of sale $-1990^{1}$ & -0.0093 & .0010 & $* * *$ & -.0033 & .0013 & $* * *$ \\
\hline Built 1991-2000 & -0.0025 & .0085 & $* *$ & -.092 & .011 & $* * *$ \\
\hline$*$ Year of sale $-2000^{1}$ & -0.0045 & .0010 & $* * *$ & .0053 & .0013 & $* * *$ \\
\hline Year dummies & Yes & & & No & & \\
\hline Postcode dummies & Yes & & & No & & \\
\hline Quarter* postcode dummies & No & & & Yes & & \\
\hline$R^{2}$ & 0.93 & & & 0.89 & & \\
\hline
\end{tabular}


effect was of the same size as in the housing services equation. The coefficients for the two isolation variables unexpectedly switch signs. Also, the discrepancies in the estimated effects of construction periods become larger.

\section{Appendix C The construction of confidence intervals}

To compute $5 \%$ confidence intervals of our quantile estimates we make use of the results of Fan and Liu (2016). We start from their equation (3) which covers a family of models and then focus on the application to local polynomial quantile regression:

$C I \sim G_{1-\alpha}=\left[\widehat{\xi}^{*}\left(p-\frac{z_{\alpha / 2} \widehat{\sigma}\left(p \mid x_{0}\right)}{c_{n}} \mid x_{0}\right), \widehat{\xi}^{*}\left(p+\frac{z_{\alpha / 2} \widehat{\sigma}\left(p \mid x_{0}\right)}{c_{n}} \mid x_{0}\right)\right]$

In this equation:

$\widehat{\xi}^{*}\left(p^{\prime} \mid x_{0}\right)$ is the estimate of the $p^{\prime}$ th quantile conditional on $x_{0}$,

$z_{\alpha / 2}$ is the upper quantile of a standard normal variable $N: \operatorname{Pr}\left(N>z_{\alpha / 2}\right)=1-\alpha / 2$

$\hat{\sigma}\left(p \mid x_{0}\right)$ is a consistent estimator of $\sigma\left(p \mid x_{0}\right)$

$c_{n}$ a positive constant.

For the application to local polynomial quantile regression Fan and Liu (2016) show that:

$\sigma\left(p \mid x_{0}\right)=p(1-p) \varpi_{x_{0}}^{2}$, with $\varpi_{x_{0}}=\|K\|_{2} / \sqrt{f_{X}\left(x_{0}\right)}$. Here $\|K\|_{2}$ is the Euclidean norm of the kernel function and $f_{X}\left(x_{0}\right)$ is the density of $X$ at $x_{0}$. Moreover: $c_{n}=\sqrt{n h_{n}^{d}}$ with $h_{n}$ the bandwidth.

For $5 \%$ confidence intervals $z_{\alpha / 2}=1.96$. For the standard normal distribution $\|K\|_{2}=0.84$. 
$\sqrt{f_{X}\left(x_{0}\right)}$ is between 0.43 and 1.07. So $\sigma\left(p \mid x_{0}\right)=p(1-p) \varpi_{x_{0}}^{2}$ is between

$0.25 *(0.84 / 0.43)^{2}=0.95$ and $0.25 *(0.84 / 1.07)^{2}=0.15$. The bandwidth equals 0.1 . For

$n=575, c_{n}=7.85$, for $n=8000, c_{n}=28.2$. 